\title{
Assessment of Soil Contamination by Gas Cloud Generated from Chemical Fire Using Metabolic Profiling and Associated Bacterial Communities
}

\author{
Jungman Jo ${ }^{1,2,+}$, Yongtae Ahn ${ }^{1,+}{ }^{\text {, Kalimuthu Pandi }}{ }^{1}$, Heesoo Pyo ${ }^{3}$, Naeun Kim ${ }^{1}$, Seong-Taek Yun ${ }^{2} \mathbb{D}^{\text {, }}$ \\ Minseok Kim ${ }^{3}$, Jeongae Lee ${ }^{3, * \mathbb{D}}$ and Jaeyoung Choi ${ }^{1,2, *}$
}

\section{check for} updates

Citation: Jo, J.; Ahn, Y.; Pandi, K.; Pyo, H.; Kim, N.; Yun, S.-T.; Kim, M.; Lee, J.; Choi, J. Assessment of Soil Contamination by Gas Cloud Generated from Chemical Fire Using Metabolic Profiling and Associated Bacterial Communities. Minerals 2021 11, 372. https://doi.org/10.3390/ $\min 11040372$

Academic Editors: Minhee Lee and Wooyong Um

Received: 27 February 2021

Accepted: 30 March 2021

Published: 1 April 2021

Publisher's Note: MDPI stays neutral with regard to jurisdictional claims in published maps and institutional affiliations.

Copyright: (c) 2021 by the authors. Licensee MDPI, Basel, Switzerland. This article is an open access article distributed under the terms and conditions of the Creative Commons Attribution (CC BY) license (https:/ / creativecommons.org/licenses/by/ $4.0 /)$.
1 Center for Environment, Health and Welfare Research, Korea Institute of Science and Technology, Hwarang-ro 14, Seongbuk-gu, Seoul 02792, Korea; jjmwork1769@gmail.com (J.J.); ytahn@kist.re.kr (Y.A.); ponnupandi266@gmail.com (K.P.); naeun4541@gmail.com (N.K.)

2 Graduate School of Energy and Environment, Korea University, 145 Anam-ro, Seongbuk-gu, Seoul 02841, Korea; styun@korea.ac.kr

3 Molecular Recognition Research Center, Korea Institute of Science and Technology, Hwarang-ro 14, Seongbuk-gu, Seoul 02792, Korea; phs3692@kist.re.kr (H.P.); min4k@hotmail.com (M.K.)

* Correspondence: frans@kist.re.kr (J.L.); jchoi@kist.re.kr (J.C.); Tel.: +82-2-958-5846 (J.C.)

$+\quad$ These authors contributed equally to the paper.

\begin{abstract}
Chemical accidents have frequently occurred in South Korea as a result of the huge amount of chemicals being used in various industries. Even though fire accidents accounted for $71.9 \%$ of chemical accidents during 2008-2018 in South Korea, most ecological research and investigation has focused on leakage accidents since most fire or explosion gases are diffused out and disappear into the atmosphere. In this study, the possibility of soil contamination by toluene combustion is proposed. A fire simulation batch test was performed and identified the combustion by-products such as methylbenzene, ethylbenzene, ethynylbenzene, benzaldehyde, 1-phenyl-1-propyne, naphthalene, 2-methylindene using gas chromatography coupled with mass spectrometry (GC-MS). Naphthyl-2-methyl-succinic acid, a metabolic intermediate of naphthalene metabolism derived from the combustion product of toluene, was also discovered in field soil and the secondary metabolites such as streptomycin 6-phosphate, 3-Nitroacrylate, oxaloacetate using LC-MS. Moreover, Streptomyces scabiei, participating in naphthalene metabolism, was also discovered in filed soil (contaminated soil) using 16s rRNA sequencing. As a result, bacterial stress responses in field soil (contaminated soil) affected by gas cloud were identified by discovering metabolites relating to bacterial self-defense action such as fatty biosynthesis. This study draws a conclusion that soil can be polluted enough to affect bacteria by gas cloud and soil bacteria and can encounter stress for a long term even though toluene and its combustion products had already decomposed in soil.
\end{abstract}

Keywords: combustion; toluene; chemical accident; metabolomics; 16s rRNA

\section{Introduction}

Chemical accidents have occurred in South Korea consequent to the huge amount of chemicals used in various industries [1]. Even though fire and explosion accounted for $71.9 \%$ of total chemical accidents during 2008-2018 in Korea, most of the research has focused on chemical leakage accidents [2]. This might be due to a preconception that most fire or explosion gases tend to diffuse out and disappear into the atmosphere or photo-decomposed by ultra-violet of the sun [3-5], while chemical leakage can lead to contamination of the soil with a high concentration. It is questionable whether the chemical and its combustion by-product in the gas cloud, generated from a fire and explosion, affect the soil bacterial community and its metabolites for a long term since the chemical accident had occurred. Long-term risk assessment on contaminated sites by gas cloud has been poorly understood until now. On the other hand, there is another report that 
toxic substances in combustion gas cloud affect the soil ecology system. According to [6], chlorobenzene's combustion gases generated after fire and explosion can reach the soil even far from the accident site using the ADORA (Atmospheric Dispersion Of Reactive Agents) model (prediction model of gas diffusion in the atmosphere). Accordingly, the ecological impact of gas-affected soil where chemical fire accidents actually occur needs to be investigated using microbial-metabolic profiling and associated bacterial communities. This study focused on the toluene fire accident and its influence on contaminated soil. Toluene accidents have occurred most frequently out of using organic chemicals in the industry field, and it is one of the dangerous toxic substances [2,7]. Toluene is a representative hydrophobic organic pollutant and is a long-term source of soil and aquifer contamination [8]. Contaminants might penetrate the ground soil, adsorb on natural soil, and act as a potential pollution source and it could result in toxicity to soil organisms [9]. Herein, a batch experiment was performed, which reproduces the fire accident of toluene, and then transportation and adsorption of combustion products onto the soil were proposed in this study. This lab-scale batch experiment was conducted to identify the name of combustion products that remained in the gas cloud in imitation of an actual chemical accident happening. There have been theoretical and computational calculations to expect the expected combustion products of toluene [10], but this study performed the batch experiment to increase the reproducibility of actual fire accidents.

Gas chromatography coupled with mass spectrometry (GC-MS) was also utilized to identify combustion products in the gas cloud and remained chemicals in soil affected by toluene combustion in this study. Then, non-target metabolomics on soil located near chemical accident site was also performed based on LC-MS to identify metabolites in contaminated soil affected gas cloud generated from fire accident and further explored the metabolic response mechanisms in that soil. Moreover, analysis of bacterial community was performed using 16s ribosomal RNA (rRNA) sequencing surviving in contaminated soil near an actual chemical accident site.

The specific objectives in this study are (1) identify combustion compounds in gas cloud generated from chemical combustion and study the transportation and adsorption of combustion products on ground soil, (2) propose a relationship between the chemical combustion by-products and excavate the secondary metabolites indicating trace of contamination in field soil (contaminated soil), and (3) to monitor the alteration of the microbial community of soil before and after exposure of a chemical accident. Further, this study will make it possible to determine which ground soils around the chemical accident site were contaminated by gas cloud using excavating biomarkers such as secondary metabolites in field soil (contaminated soil). Moreover, this research can suggest the scientific technique to estimate the soil ecological health comparing metabolites between contaminated soil and not one.

\section{Materials and Methods}

\subsection{Identification of Combustion Products in Gas Cloud and Pollutants Remained in the Soil under Laboratory Condition}

Fire simulation tests were performed to identify the combustion products in the gas cloud. An iron chamber $(60 \mathrm{~cm} \times 60 \mathrm{~cm} \times 100 \mathrm{~cm})$ was used for the toluene combustion with flame, and butane gas was used as a fuel with burner (Camp1 plus, Kovea, Bucheon, Korea) (Figure 1a). Toluene combustion was initiated by contacting $10 \mathrm{~mL}$ toluene (anhydrous, purity $99.8 \%$, product No. 244511, Sigma Aldrich, Saint Louis, MO, USA) with butane gas flame for $30 \mathrm{~min}$ in the chamber continuously. Then, the generated gas cloud was transported to $\mathrm{n}$-hexane, methyl alcohol, and distilled water by diaphragm pump (flow rate: $1 \mathrm{~mL} / \mathrm{min}$ ). A $100 \mathrm{~mL}$ of n-hexane, methyl alcohol, and distilled water in serum glass bottles ( $140 \mathrm{~mL}$ volume capacity) were arranged by turns to dissolve the products in the combustion gas. The long needle was used and immersed into the solvent to dissolve gas and the short needle for the gas outlet reached the headspace inside the serum glass bottle. Polytetrafluoroethylene (PTFE) hose was connected with all the needles stuck in the rubber stopper of serum glass bottles. After finishing the combustion of the chemical, only 
n-hexane was obtained for analysis using GC-MS to identify combustion products in order to separate the combustion products closing to non-polarity (Figure 1b).

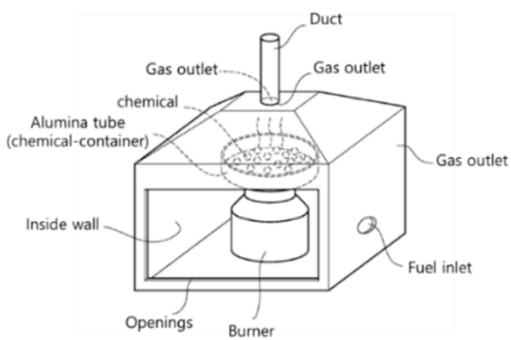

(a)

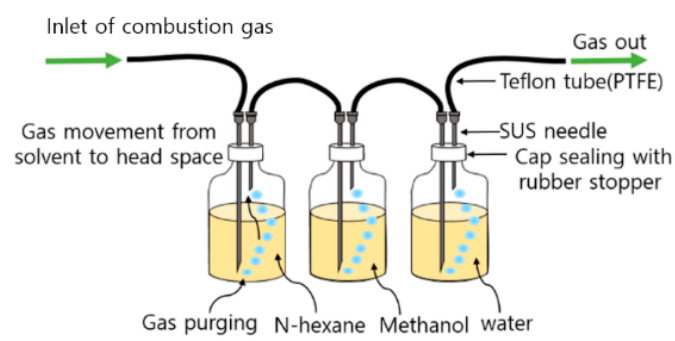

(b)

Figure 1. Schematic diagram of apparatus for combustion experiment (instruments and apparatus for fire simulation batch test) shows (a) iron chamber for chemical combustion and (b) arrangement of three solvents that can dissolve combustion products generated in fire simulation batch test.

To test the feasibility of soil contamination by gas cloud, several apparatuses were prepared. The non-contaminated soil was sampled at the site located $1 \mathrm{~km}$ apart from the chemical accident site. Then, the soil was packed in a cylinder glass column (height $20 \mathrm{~cm}$, Inner diameter $10 \mathrm{~cm}$ ) and the generated gas cloud from toluene combustion by flame ignition was continuously passed through the soil packed in a glass column for an hour by a diaphragm pump (gas flow rate: $1 \mathrm{~mL} / \mathrm{min}$ ). After the experiment, $10 \mathrm{~g}$ soil in a glass column was extracted with $40 \mathrm{~mL}$ of $\mathrm{n}$-hexane and filtered with a polyvinylidene fluoride (PVDF) filter $(0.22 \mu \mathrm{m})$. Then, filtered hexane solution was analyzed using GC-MS to identify combustion products that remained in the gas-contaminated soil. The analytical standards such as ethylbenzene (product No. 03079), ethynylbenzene (product No. 117706), benzaldehyde (product No. 09143), 1-phenyl-1-propyne (product No. 161241), naphthalene (product No. 84679), 2-methylindene (product No. 449431) were purchased from Sigma Aldrich. The instrumental setup condition is mentioned in Appendix A in detail.

\subsection{Extraction of Metabolites in Contaminated Soils (Field)}

\subsubsection{Soil Sampling and Metabolite Extraction in Field Soil (Chemical Accident Site)}

The soil samples were collected at Gimpo, in Gyeonggi Province, South Korea, where the toluene fire accident actually occurred in 2016. Soil samples were collected three times every three months from February 2019 to August 2019 and sampled every $100 \mathrm{~m}$ from $100 \mathrm{~m}$ to $500 \mathrm{~m}$ points apart from the accident site along the expected direction (northeast) of gas diffusion when the chemical accident occurred. The depth of sampling was $50 \mathrm{~cm}$ from the topsoil in order for small root hairs living in soil not to be included in the soil sample [11]. The collected soils were screened with a 10-mesh sieve ( $2 \mathrm{~mm}$ diameter) and mixed homogeneously. Then, soil samples were stored at $-80^{\circ} \mathrm{C}$ in a deep freezer right before soil extraction to avoid deformation of bacteria community and its metabolites; for extracting the metabolites from the soil, $20 \mathrm{~g}$ soil and $40 \mathrm{~mL}$-hexane were mixed in a glass vial and vortexes with a cap. Then, the vials were sonicated for 30 min with iced-cool water and the supernatant of n-hexane and soil mixture in a glass vial was filtered with a PVDF membrane filter $(0.22 \mu \mathrm{m})$. Then, the filtered $n$-hexane solution in the vial was evaporated by the continuous flow of nitrogen gas until all the solution completely dries up inside the vial. After evaporation, $3 \mathrm{~mL}$ isopropanol (product No.34863, Sigma Aldrich, for HPLC, 99.9\%) was added in order to dissolve the dried and remained residues attached to the internal surface inside the vial, and then the vial with a cap was sonicated for $30 \mathrm{~min}$ in an ice-cold water bath for better performance. After all processes, sonicated isopropanol solution in the vial was analyzed as a sample by ultra-high-performance liquid chromatography (UHPLC) system coupled with Orbitrap-MS for metabolomics. The instrumental setup condition is mentioned in Appendix A in detail. 


\subsubsection{Bacterial Community Identification (Field)}

The method of 16s rRNA sequencing was nearly the same as the previous research of the authors [12]. The soil sample was collected at Gimpo, in Gyeonggi Province, South Korea, where the toluene fire accident actually occurred in 2016. The soils were collected each 100 meters apart from the site of the accident along the diffusion direction of the gas cloud when the chemical accident occurred. The collected soils were screened with a 10-mesh sieve ( $2 \mathrm{~mm}$ diameter) and mixed homogeneously. The microbial communities in soil were first extracted using a PowerSoil DNA Extraction Kit (Mobio Laboratories, USA). All soil samples were sieved to remove stones and leaves. The QC (Quality Control) analyses of the DNA of all samples were performed using NanoDrop ND-8000 (Thermo Fisher Scientific Inc., Waltham, MA, USA). The bacterial primer sets used included 341F $\left(5^{\prime}\right.$ CCTACGGGNGGCWGCAG $\left.3^{\prime}\right)$ and 805Rmod (5' GACTACNVGGGTWTCTAATCC $\left.3^{\prime}\right)$. The total metagenomic DNA was subjected to PCR amplification by targeting a $460 \mathrm{bp}$ fragment of the 16S rRNA regions V3-V4. For PCR amplification, an initial denaturation was performed for $3 \mathrm{~min}$ at $95^{\circ} \mathrm{C}$, followed by annealing at $95^{\circ} \mathrm{C}$ for $30 \mathrm{~s}$, primer annealing at $55^{\circ} \mathrm{C}$ for $30 \mathrm{~s}$, extended annealing at $72{ }^{\circ} \mathrm{C}$ for $30 \mathrm{~s}$ and final annealing at $72{ }^{\circ} \mathrm{C}$ for $5 \mathrm{~min}$. The PCR products were identified using $1 \%$ agarose gel electric shock visualized under the Gel Doc System (BioRad, Hercules, CA, USA). After correcting amplified organisms with CleanPCR (CleanNA), the purified products of equal concentration were collected and put together, and then short fragments (non-targeted products) were removed using CleanPCR (CleanNR). A DNA 7500 chip was used with the Bioanalyzer 2100 (Agilent, Santa Clara, CA, USA) to evaluate the quality and size of products. Sequencing was performed using the Illumina MiSeq Sequencing System (Illumina, Diego, CA, USA) in Chunlab, Inc (Seoul, Korea). The MiSeq pipeline method is based on the EzBioCloud database. Raw read processing started with Trimomatic 0.321 for quality inspection and filtering low quality $(<\mathrm{Q} 25)$. After the QC pass, two-way sequence data were merged using PANDAseq2. The trim primer was reduced to a similarity of 0.8 using ChunLab's program. Reduced-noise sequences used DUDE-Seq4, and non-replicated reads were extracted by UCLUST5. The EzBioCloud database was used for taxonomic allocation using USEARCH (8.1861_i86linux32) 5 and more accurate pairwise alignment 6 . Readings not identified as species level ( $<97 \%$ similarity) were compiled in the EzBioCloud database, and UCLUST5 and CDHIT8 were used to perform de novo clustering to create additional operational taxonomic units (OTUs). Finally, any OTU with a single read (single tone) was omitted from further analysis, while alpha diversity index 8-13, lean curve 14, and ranking rich curve 15 were estimated using an internal code. EzBioCloud was used to determine the microbial community composition of each sample and Krona.

\subsubsection{Statistical Analysis}

LC-MS raw data were deconvoluted and peak aligned using PROGENESIS QI software (Version 3.0, Waters company, Milford, MA, USA). The data deconvolution process was performed in a high-resolution mode. To make a score plotting (partial least squaresdiscriminant analysis (PLS-DA)), the data were imported to SIMCA software version 16 Umetrics (Sartorius, Umeå, Sweden). The raw data were treated with Pareto scaling for PLS-DA. Then, the load plotting was processed to extract high variable importance in projection (VIP) value. In order to identify the analyzed metabolites, which were sorted using the screening criteria (VIP $>1$ from SIMCA 16.0), had over 700 variables been obtained. To perform statistical analysis using Metaboanalyst 5.0, data were normalized by sum, Pareto-scaled, and relative standard deviation (RSD) filter. To extract the variables less than $p$-value 0.05 , a $t$-test was also performed (cut-off value of 0.05 raw $p$-value). The screened variables were visualized into heat map analysis and identified by web server mass translator into pathways (MassTRIX) with the option of $0.01 \mathrm{Da}$ of mass error using the database "KEGG/HMDB/LipidMaps without isotopes." The identified metabolite information after MassTRIX was then imported into the MetaboAnalyst 5.0 web software (https: / / www.metaboanalyst.ca) (accessed on 1 February 2021) to determine which 
metabolic pathways were disturbed by the modeling. To improve the visualization of the difference in the metabolite peak intensity between the contaminated soil and control soil, semi-identified metabolites were used for the clustering, heat map analysis, pathway analysis, and metabolites.

\section{Results and Discussion}

\subsection{Identification of Combustion Products in Gas Cloud Generated from Toluene Combustion}

A simulation test for toluene combustion was conducted in order to identify combustion products formed in a gas cloud and the compounds polluting the ground soil, using GC-MS. The detected compounds could be produced in the gas cloud after a fire accident occurs (Table 1). Total ion chromatogram is presented in Figure S1. Those were unburned methylbenzene (toluene), ethylbenzene, ethynylbenzene, benzaldehyde, 1-Phenyl1-propyne, naphthalene, and 2-methylindene. The above-mentioned combustion products were obtained using GC-MS, which are expected to exist in the gas cloud generated during a chemical fire (Figure 2).

Table 1. List of combustion products in a gas cloud using gas chromatography coupled with mass spectrometry (GC-MS).

\begin{tabular}{ccccc}
\hline Combustion Product & Formula & $\begin{array}{c}\text { Molecular } \\
\text { Weight }\end{array}$ & $\mathbf{t}_{\mathbf{R}}(\mathbf{m i n})$ & $\begin{array}{c}\text { Selected Ions } \\
(\mathbf{m} / \mathbf{z})\end{array}$ \\
\hline Methylbenzene & $\mathrm{C}_{7} \mathrm{H}_{8}$ & 92.14 & 3.973 & $91,92,65$ \\
Ethylbenzene & $\mathrm{C}_{8} \mathrm{H}_{10}$ & 106.17 & 7.030 & $106,91,51$ \\
Ethynylbenzene & $\mathrm{C}_{8} \mathrm{H}_{6}$ & 102.13 & 7.869 & $102,76,50$ \\
Benzaldehyde & $\mathrm{C}_{7} \mathrm{H}_{6} \mathrm{O}$ & 106.12 & 8.997 & $106,77,51$ \\
1-Phenyl-1-propyne & $\mathrm{C}_{9} \mathrm{H}_{8}$ & 116.16 & 9.926 & $116,115,63,89$ \\
Naphthalene & $\mathrm{C}_{10} \mathrm{H}_{8}$ & 128.17 & 11.218 & $128,127,102$ \\
2-Methylindene & $\mathrm{C}_{10} \mathrm{H}_{10}$ & 130.19 & 13.154 & $130,129,115$ \\
\hline
\end{tabular}

$\mathbf{t}_{\mathbf{R}}$ : retention time.

A variety of research had already proved the mechanism of the formation of those products mentioned above. It is notable that naphthalene is a major pollutant in soil because naphthalene-related metabolites were discovered near the chemical accident site. The authors of [13] stated the principle of naphthalene and 2-methylindene formation from toluene combustion. According to [10,13], naphthalene and 2-methylindene through radical reaction can be formed from indenyl molecules. If the indenyl molecule has a bond with the methyl group, it leads to methylindene. Accordingly, it seems that 2-methylindene can be formed if the methyl group attaches to the 2-carbon position of methylindene. Then, if one hydrogen atom is taken away from 2-methylindene or 2-methyl-2H-indene, it goes to 2-methlindenyl; in addition, one hydrogen abstraction from the former molecule leads to naphthalene production. There is also another pathway of naphthalene production. When 1-methylindene drops down one hydrogen atom, 1-methlindenyl radical can be formed with the radical transition. Then, one hydrogen removal causes naphthalene production. The formation of naphthalene and 2-methylindene is described in Figure S2.

Phenyl radical contributes to ethenylbenzene formation through the Frenklach route [14] $\mathrm{C}_{8} \mathrm{H}_{7}$ radicals would be formed by the radical reaction of $\mathrm{C}_{6} \mathrm{H}_{5}$ and $\mathrm{C}_{2} \mathrm{H}_{2}$. If $\mathrm{C}_{8} \mathrm{H}_{7}$ radical accepts one hydrogen atom, ethenylbenzene can be produced. Another report also proved that styrene production from toluene combustion with butanol flame [15]. The explained products generated from toluene combustion can be phenylacetylene (ethynylbenzene), styrene (ethenylbenzene), ethylbenzene, indenyl, indene, and naphthalene. Through this batch test, these combustion products have the potential to reach and contaminate the ground soil when a toluene fire accident occurs.

Transportation and Adsorption of Combustion by-Products onto Soil.

As for the diffusion and transportation of a gas cloud in the air, it is a general concept that most gases diffuse out and expand to the atmosphere around and become photodegraded. However, the gas cloud can spread to the ground soil under specific atmospheric 
conditions. The gas diffusion moving downward to the ground level can contaminate the soil, as shown in Figure 2. This scenario is suggested by [6] about studying chlorobenzene fire and explosion accidents using the ADORA model. This model predicts the gas expansion and transportation to the ground level-based on energy, momentum, and thermochemical equilibrium. When a fire or explosion happens, a generated massive heat immediately gets to be emitted for a short term forming a super high temperature under the high pressure. Then, secondary combustion called "afterburn" can occur causing the vertical elevation of the gas cloud with the end of the first explosion blast. Most incomplete or toxic compounds can be formed at this point. After quite a while, the gas cloud does not elevate upward until its gas density would be increasingly similar to the density of the air around. After emitting massive heat energy, the movement of the gas cloud becomes more influenced by wind flow while gas density in the gas cloud decreases. Conclusively, downdraft transports pollutants passively to reach the ground soil, as reported by Moussa and Devarakonda [6]. Moreover, the atmospheric condition has to be also considered. The rapidly cooled ground or inflow of chilly air right above ground at midnight makes it possible for airborne pollutants to reach the ground. After sunset, the ground cools down, and the air in touch with the ground becomes cooler increasingly. The relatively warmer air goes upward and the cooler one goes down to the ground [6,7]. Due to this air condition, the inversion layer makes the high concentration of pollutants close to the ground because this inhibits the gas diffusion and elevation to the upper atmosphere and trap the contaminants such as combustion products below the inversion layer.

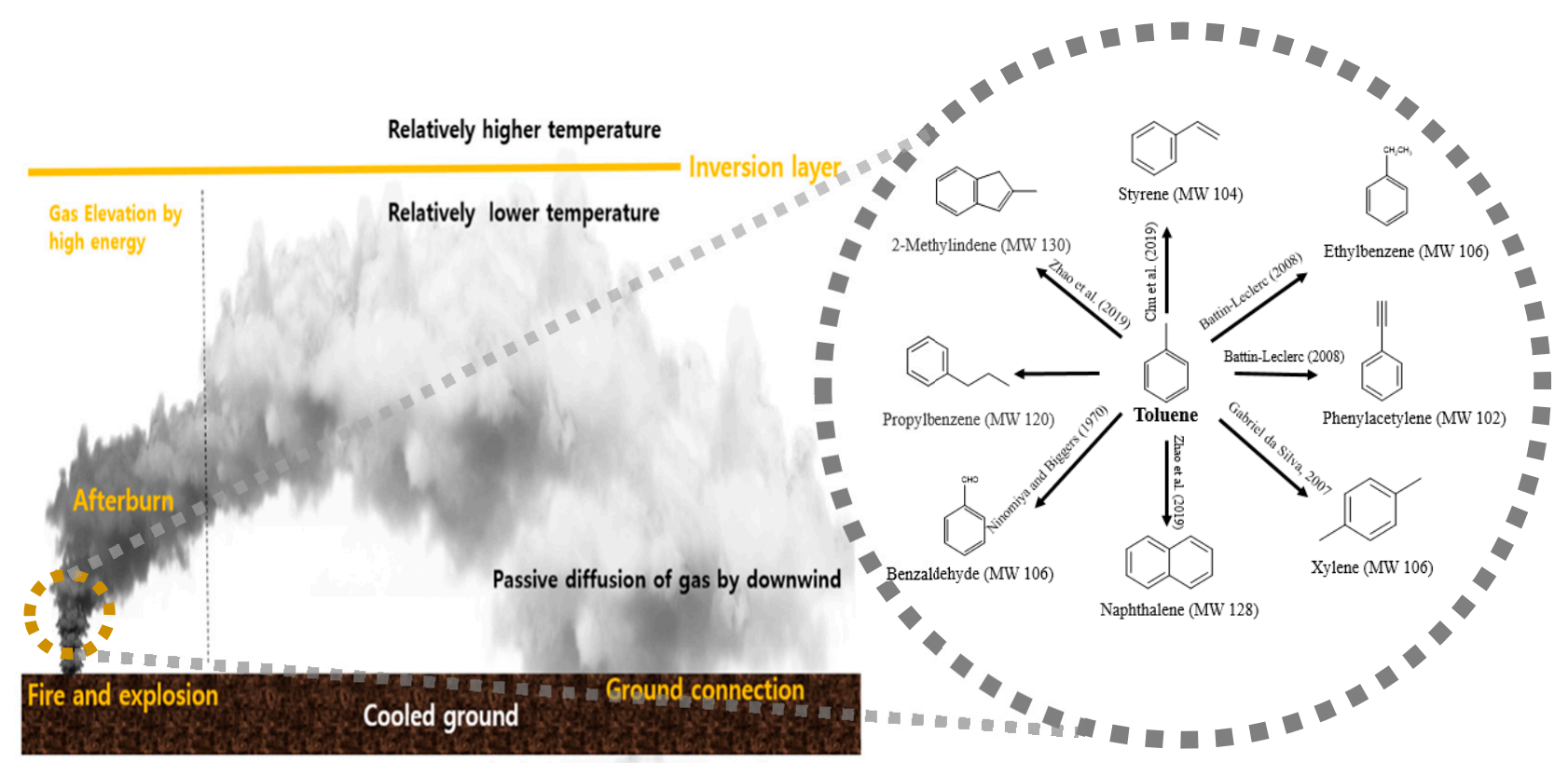

Figure 2. Modified image explaining soil pollution by gas cloud under the inversion layer, as suggested by [6], and schematic diagram showing the expectable combustion products with the formation mechanism proved by the following literature; 2-methylidene [10,13], toluene to ethenylbenzene (styrene) [13], toluene to ethylbenzene [14], toluene to ethynylbenzene (phenylacetylene) [14], toluene to xylene (dimethylbenzene) [16], toluene to naphthalene, toluene to benzaldehyde [17].

Considering the actual toluene fire accident mentioned in this study, which happened at 2 a.m. in South Korea, it is reasonable that the inversion layer and cooled ground with downdraft can be formed at the accident site and contribute to ground contamination by the gas cloud at that time (Figure 2). In addition, internal boundary layers (IBLs) formation also can cause the gas cloud to reach the ground around the coastal industry complex [18]. Considering the actual chemical accident site was located near the coast, this theory would be much persuasive for assuming IBLs formation. Above all, the downdraft in the air must be an essential factor for highly ground pollution of airbornecontaminants such as combustion products in a gas cloud. Adsorption of combustion 
products to the ground soil also has to be discussed. It has been reported that black carbon or soot, one of the incomplete combustion products, generated from the combustion of an organic chemical can be deposited in the soil [19]. There is a strong bond between the minerals in soil. Joaquia et al. studied the sorption of volatile organic compounds (VOCs) onto soil minerals; they performed the experiment about the sorption isotherms of VOCs on soil, which has dissimilar properties, respectively, considering few parameters that include the mineralogical type and surface area [20]. Toluene, ethylbenzene, and xylene were verified to be adsorbed to soil porous media. The sorption mechanism is an ion-dipole interaction, sorption by $\mathrm{pi}(\pi)$-electron, and Van der Waals-London forces for aromatic molecules [20]. The batch experiment was also performed to identify whether combustion products can remain in the soil in this study, which reproduces the fire accident of toluene and transportation and adsorption of combustion products onto the soil. Toluene, ethylbenzene, 2-methylindene, out of suggested combustion products, were identified in the soil using GC-MS (Table 1).

Referring to Table 2, soil $\mathrm{pH}$ ranges from the neutral $\mathrm{pH} 6.14$ to 8.29 and total organic carbon is maximally $1.05 \%$. There is a possibility that actually contaminated soil can have the sorption capability for binding organic materials to clay and its mineral. The cation exchange capacity (CEC) of these soil samples has a relatively higher value than that in one of the other studies comparing the average CEC value, i.e., $10 \mathrm{cmol} / \mathrm{kg}$ in South Korea [21]. It is assumed that most combustion products can attach onto fine particles containing clay minerals that have a spacious surface area, according to Breus and Mishchenko [22]. Thus, clay minerals, kaolinite, halloysite, and anorthite discovered in actually contaminated soil located chemical accident site, have a potential to adsorb aromatic compounds such as combustion products of toluene. Fundamental properties of soil such as $\mathrm{pH}, \mathrm{EC}$ (Electrical Conductivity), TOC (Total organic carbon), and ORP (Oxidation-reduction potential) were not significantly changed. However, a high concentration of toluene exposal can affect soil EC and ORP. This was observed in our previous study [12]. A drastic change of soil properties might depend on the high concentration and exposal time of toluene.

Table 2. Soil characterization of field soil (contaminated soil).

\begin{tabular}{|c|c|c|c|c|c|c|c|c|}
\hline \multirow{2}{*}{$\begin{array}{l}\text { Field } \\
\text { Soil }\end{array}$} & \multicolumn{3}{|c|}{ Texture (\%) } & \multirow{2}{*}{$\mathrm{pH}$} & \multirow{2}{*}{$\begin{array}{l}\text { ORP } \\
(\mathrm{mV})\end{array}$} & \multirow{2}{*}{$\begin{array}{c}\text { CEC } \\
(\mathrm{cmol} / \mathrm{kg})\end{array}$} & \multirow{2}{*}{$\frac{\text { TOC }}{(\%)}$} & \multirow{2}{*}{ Mineral } \\
\hline & Sand & Silt & Clay & & & & & \\
\hline $100 \mathrm{~m}$ & 68.57 & 15.42 & 16.01 & 7.27 & 113.4 & 21.64 & 1.05 & \multirow{5}{*}{$\begin{array}{l}\text { Kaolinite } \\
\text { Halloysite } \\
\text { Anorthite } \\
\text { Quartz }\end{array}$} \\
\hline $200 \mathrm{~m}$ & 69.42 & 15.24 & 15.34 & 6.67 & 137.8 & 29.87 & 1.05 & \\
\hline $300 \mathrm{~m}$ & 69.56 & 13.95 & 16.49 & 6.14 & 179.0 & 23.40 & 0.39 & \\
\hline $400 \mathrm{~m}$ & 57.78 & 28.54 & 13.68 & 6.97 & 106.9 & 20.76 & 0.62 & \\
\hline $500 \mathrm{~m}$ & 76.36 & 11.00 & 12.64 & 8.29 & 44.1 & 23.43 & 1.25 & \\
\hline
\end{tabular}

ORP: Oxidation-reduction potential (mV); CEC: Cation exchangeable capacity (cmol/ kg); TOC: Total organic carbon $(\%)$.

\subsection{Overview of Metabolites Discovered in Filed Soil (Contaminated Site)}

The metabolites in the soil near the accident site were excavated to trace the ecological effects and find the biomarker metabolites having a trace of toluene fire accident by identifying metabolites formed in toluene-affected soil (field soil) for three years after the chemical accident had occurred. PLS-DA was applied to assess the propensity of the metabolites. PLS-DA analyses enable highlighting differences between control and field (contaminated soil) (Figure 3). PLS-DA results showed a clear separation of contaminated soils located within $500 \mathrm{~m}$ and control soil located at $1 \mathrm{~km}$ away from the chemical accident site. 


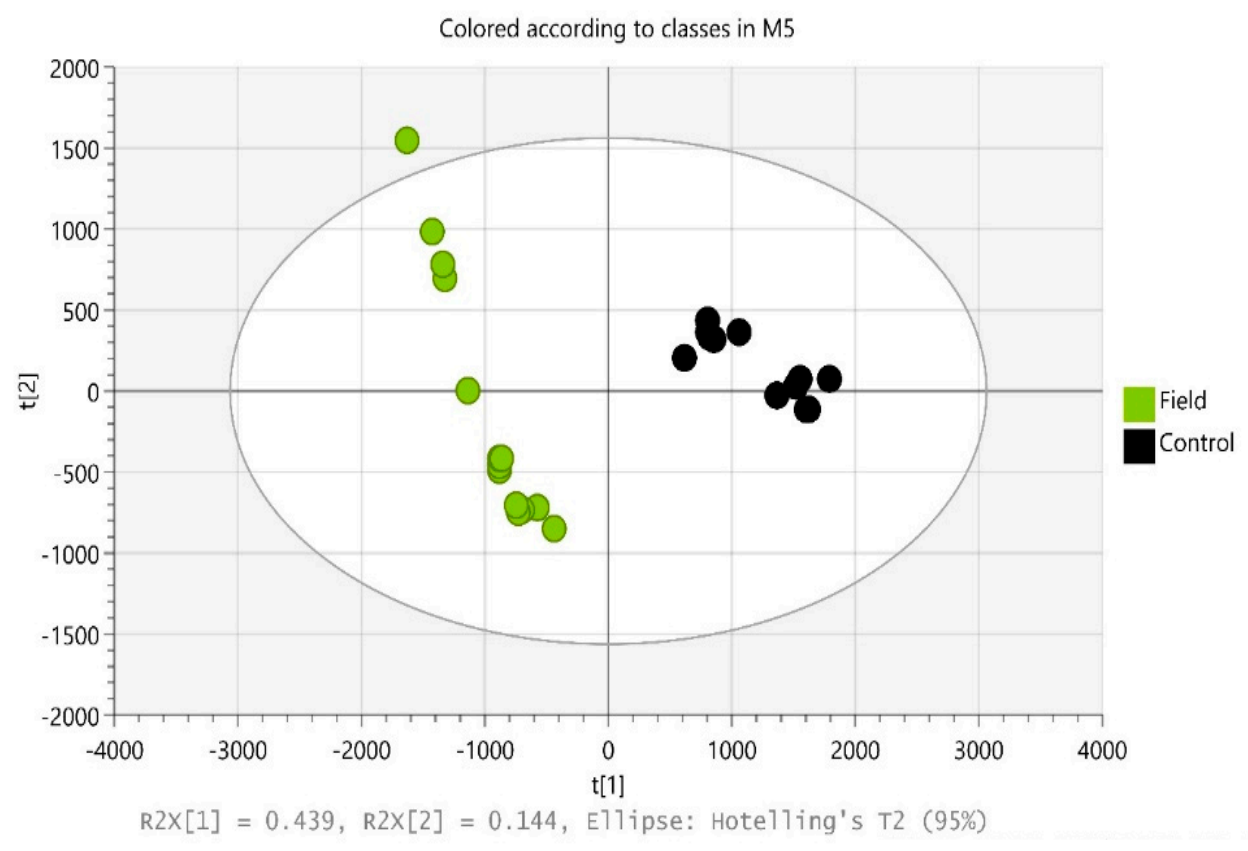

Figure 3. Partial least squares-discriminant analysis (PLS-DA) including control (not contaminated) and field (contaminated soils) using ultra-high-performance liquid chromatography (UHPLC)Orbitrap-MS; (control is not contaminated soil located $1 \mathrm{~km}$ away from the accident site, field is contaminated soil located from $100 \mathrm{~m}$ to $500 \mathrm{~m}$ away along the diffusion direction of gas cloud at the accident site).

Figure 3 shows that field soil does not currently recover metabolically comparing control soil (not contaminated soil) because the "field" group is not close to the "control" group on the PLS-DA score plot, which means components of metabolites (variables) in two soil groups are quite different. Each group was tightly clustered. The heat map shown in Figure 4 displays different levels among the two groups and metabolites with similar variation trends that were clustered together. Overall, 114 metabolites (variables) less than $0.05 p$-value were shown in the heat map analysis. The distribution of the metabolites group can be divided into two groups of A and B (Figure 4). The black vertical line distinguishes the group control and field groups, while the black horizontal line divides metabolite categories such as up- and downregulation of metabolites in field soil. The metabolites in group A are considered inhibited and downregulated metabolites in field soil and the metabolites in group B are upregulated in field soil (Figure 4). The metabolic result of the field group soil in the heat map still presents several metabolites derived from toluene or its combustion products (Figure 4 and Table 4 ).

The metabolic pathway analysis result shows the major metabolism in the chemical accident site (Figure 5 and Table 3). The metabolisms of alanine, aspartate, and glutamate satisfied the cut-off standard of raw $p$-value less than 0.05 , which means significant and major metabolism in field soil (Figure 5). The oxaloacetate and carbamoyl phosphate discovered in field soil joined this metabolism. According to [23], upregulation of oxaloacetate can lead to the generation of nicotinamide adenine dinucleotide phosphate (NADPH) during oxidative stress by promoting the conversion of NADH (Nicotinamide adenine dinucleotide). The reduced NADPH is significant for the cellular anti-oxidative protection. Oxaloacetate is evidence that indicates microbes struggling to overcome chemical stress. Moreover, there are several biomarker metabolites such as naphthyl-2-methyl-succinic acid involved in naphthalene degradation, streptomycin 6-phosphate in streptomycin biosynthesis, malonyl-[acyl-carrier protein] in fatty acid biosynthesis, and 3-nitroacrylate. On the other hand, down-regulated metabolites also can be a significant biomarker. There are microbiologically inhibited metabolites in field soil (contaminated soil) suggested in group A site in the heat map and those metabolites (Table 4), which are based on $p$-value 
and t.stat ( $t$-test result) value by screening the variables (metabolites) through $t$-test, include selagine, 2-Iodophenol, and 3beta-(1-pyrrolidinyl)-5alpha-pregnane-11,20-dione and are considered major downregulated metabolites in field soil. Moreover, phytoceramide also discovered in sphingolipid metabolism was downregulated in field soil (contaminated soil). According to [24], sphingolipids are common components of cell membranes of eukaryotic microbes, and this plays an important role in cell motility and growth. Sphingolipids are also signaling molecules, regulating many important cellular processes related to apoptosis and autophagy [25]. Inhibition of this metabolism in field soil (contaminated soil) is questionable because upregulation of fatty acid biosynthesis for protecting bacterial cell membrane was discovered in field soil. However, it is clear that bacteria cannot activate sphingolipid metabolism due to chemical stress or unknown reason. Further research is needed to understand the reason why this metabolism becomes inhibited.

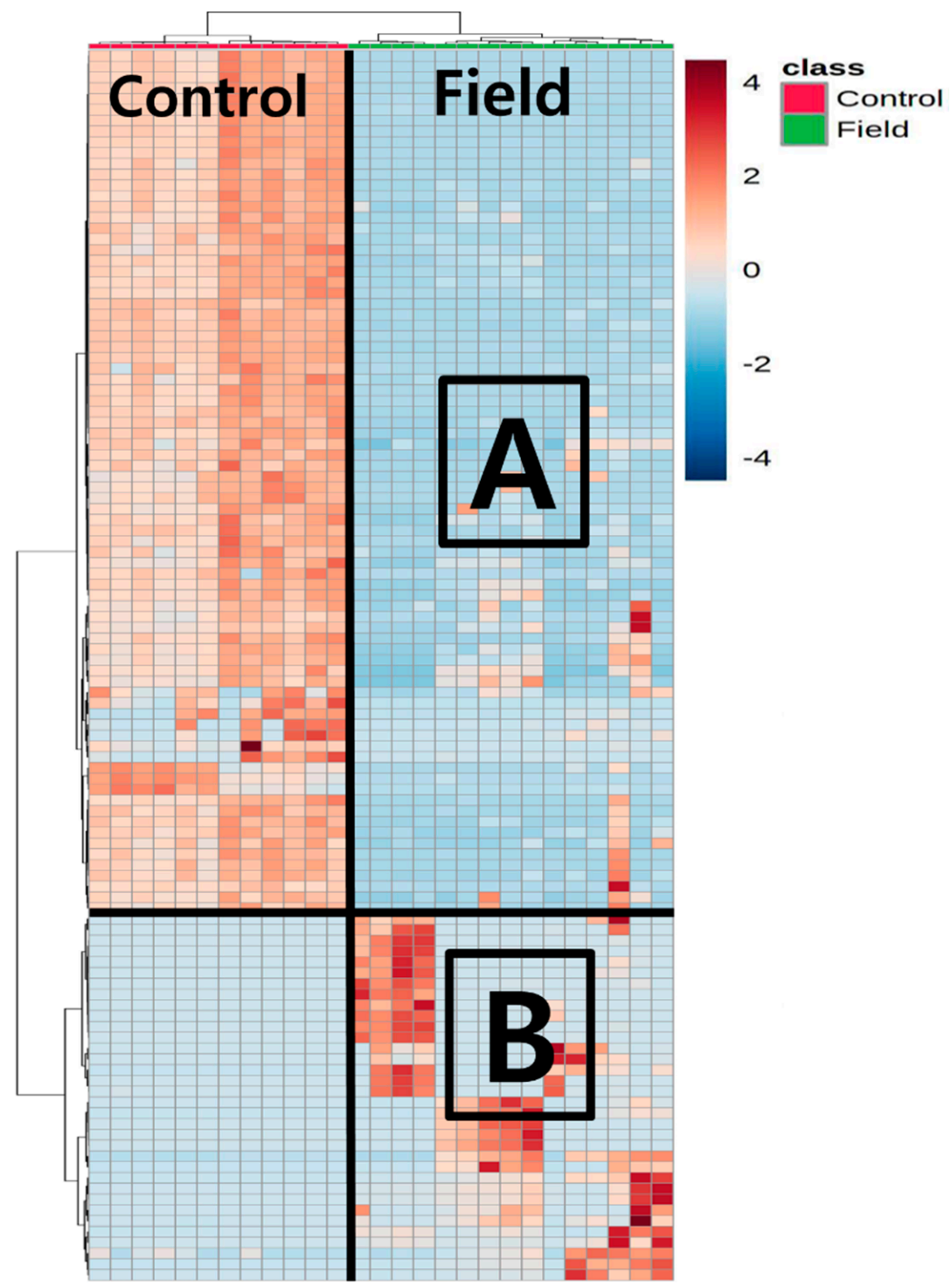

Figure 4. Heat map visualization of control (not contaminated soil) and field (contaminated soil); a total of 114 variables shown in heat map filtered by $p$-value $<0.05$ through $t$-test. Metabolites in A site means downregulation of metabolism due to soil contamination and metabolites in B site means upregulation of metabolism due to soil contamination. The metabolites shown in heat map analysis are suggested in Table 4 . 


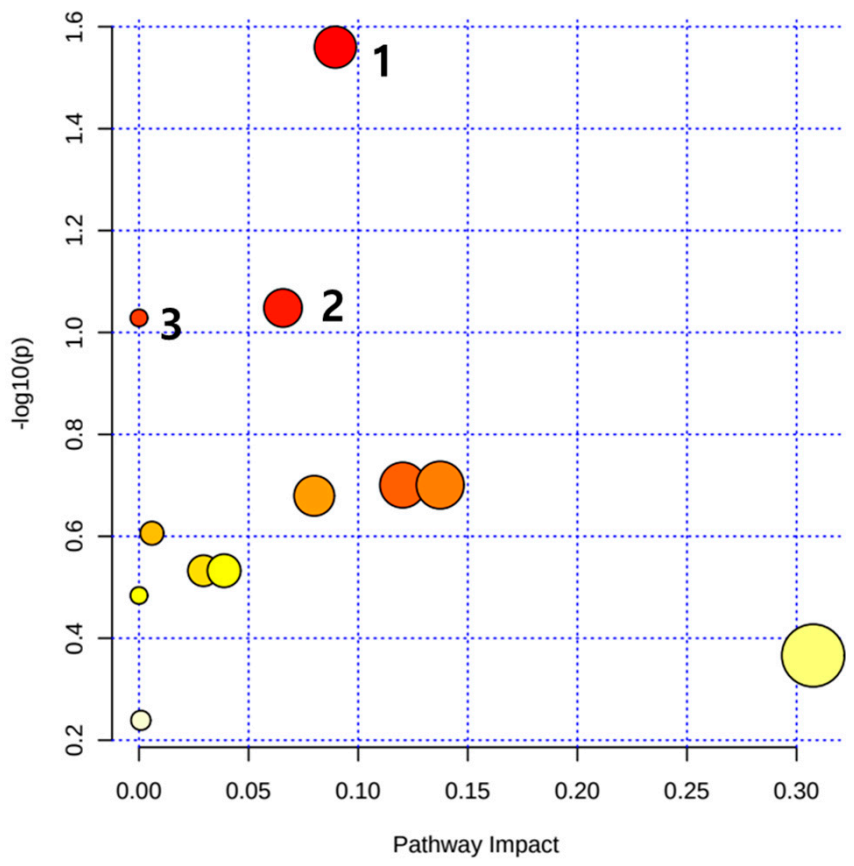

Figure 5. Metabolic pathway analysis of field Soil (contaminated soil). 1: Alanine, aspartate and glutamate metabolism, 2: Pyrimidine metabolism. 3: Nitrogen metabolism.

Table 3. Metabolic pathway analysis of field Soil (contaminated soil).

\begin{tabular}{ccccccc}
\hline No. & Metabolism & Total & Expected & Hits & Raw $\mathbf{p}$ & LOG(p) \\
\hline 1 & $\begin{array}{c}\text { Alanine, aspartate and } \\
\text { glutamate metabolism }\end{array}$ & 22 & 0.268 & 2 & 0.0275 & 1.560 \\
\hline 2 & Pyrimidine metabolism & 42 & 0.511 & 2 & 0.0895 & 1.048 \\
\hline 3 & Nitrogen metabolism & 8 & 0.097 & 1 & 0.0936 & 1.029 \\
\hline
\end{tabular}

Three metabolisms presented in Table 3 are visualized in Figure 5. Predominant metabolism of soil bacteria in field soil. Metabolism less than the $p$-value of 0.05 is considered significant statistically. Accordingly, metabolism (LOG(p) more than 1) is meaningful metabolism. "Total" means the total number of metabolites in metabolism, and "Hits" means the number of discovered metabolites in field soil using LC-MS.

3.2.1. Propose the Relationship between Toluene Combustion Products and Metabolites in Toluene Affected Soils

There are several molecules or metabolites discovered in field soil and contaminated soil. These indicate that the combustion products in the gas cloud have still affected the soil even three years passed after the chemical accident. Herein, Table 4 shows molecules or metabolites semi-identified by MassTRIX Web Database. Those semi-identified molecules are determined based on the lowest mass error value, comparing theoretical mass and measuring mass analyzed by high-resolution mode UHPLC-Orbitrap-Mass. Dibenzofuran discovered in field soil is a polycyclic aromatic compound containing two benzene rings fused to a central furan ring. This has been suggested as one of the products from benzene combustion. Shi et al. explained that benzofuran could be formed in presence of phenoxyl radicals with flame combustion [26]. The 1,2-Dichlorobenzene is a molecule containing chlorine atoms with benzene compounds. This is a derivative of benzene as the most remarkable evidence, which proved field soil around chemical fire accident site had been contaminated by gas cloud. This molecule has the lowest t.stat and $p$-value, which is the most upregulated metabolite in field soil, compared to control soil (Table 4). This implies a pollutant related to benzene compounds had strongly affected the soil in the past. 


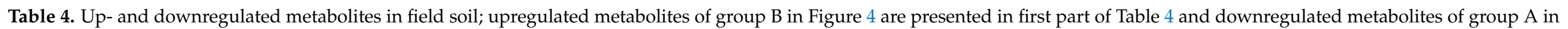

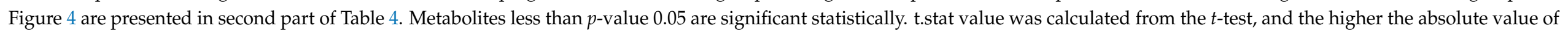
t.stat, the greater the difference in intensities of metabolites when comparing control soil and field soil groups.

\begin{tabular}{|c|c|c|c|c|c|}
\hline \multicolumn{6}{|c|}{ Upregulated Metabolites in Field Soil (Contaminated Soil) } \\
\hline$t_{R}(\min ) \_m / z$ & t.stat & $p$-Value & Mass Error (ppm) & Metabolite & Metabolism \\
\hline 15.43_146.9797 & -4.3983 & 0.00060457 & -23.25573074 & 1,4-Dichlorobenzene & Derivative of benzene ring \\
\hline 15.47_265.9916 & -2.3449 & 0.034295 & -12.07499801 & 2-Hydroxy-beta-keto-L-tyrosyl-[pcp] & Novobiocin biosynthesis \\
\hline 14.37_139.9872 & -2.7065 & 0.017037 & 58.77534925 & 3-Nitroacrylate & Beta-nitroacrylate reductase \\
\hline 0.95_182.9844 & -2.533 & 0.023891 & -13.43082261 & 5-Chloro-1,2,4-trihydroxybenzene & Chlorocyclohexane and chlorobenzene degradation \\
\hline 15.92_686.1990 & -2.2594 & 0.04031 & 14.99536091 & Acarbose & Acarbose and validamycin biosynthesis \\
\hline 13.87_149.0227 & -2.6871 & 0.017691 & -11.97984821 & Hydroxyhydroquinone & $\begin{array}{c}\text {-Chlorocyclohexane and chlorobenzene degradation } \\
\text {-Benzoate degradation } \\
\text {-Aminobenzoate degradation }\end{array}$ \\
\hline 15.46_371.1010 & -2.2147 & 0.04387 & -2.081103867 & Camptothecin & -Biosynthesis of alkaloids derived from shikimate pathway \\
\hline 14.60_141.9825 & -2.9159 & 0.01128 & 52.71728653 & Carbamoyl phosphate & Purine metabolism \\
\hline 15.90_371.1008 & -2.5188 & 0.024559 & -11.12892128 & Ciprofloxacin & ABC transporters \\
\hline 15.00_207.0162 & -2.4157 & 0.029955 & 21.61279894 & Dibenzofuran & Derivative of benzene ring \\
\hline 13.83_279.1582 & -2.8061 & 0.014008 & 3.172566133 & Dibutyl phthalate & \\
\hline 15.47_429.0878 & -2.1947 & 0.045551 & -3.571806454 & Diethylstilbestrol diphosphate & \\
\hline $15.42 \_445.1191$ & -2.3952 & 0.031151 & -13.87669464 & Granaticin & Biosynthesis of type II polyketide products \\
\hline 0.98_158.9613 & -2.5656 & 0.022428 & -63.07337885 & Malonyl-[acyl-carrier protein] & Fatty acid biosynthesis \\
\hline 15.97_663.4559 & -3.0953 & 0.0079051 & -72.40067762 & Mosesin 4 & \\
\hline 15.47_298.0540 & -2.5857 & 0.021568 & -4.498039682 & $\begin{array}{l}\text { Naphthyl-2-methyl-succinic acid } \\
\text { (Streptomyces scabiei) }\end{array}$ & $\begin{array}{l}\text { Naphthalene degradation } \\
\text { Degradation of aromatic compounds }\end{array}$ \\
\hline
\end{tabular}


Table 4. Cont

\begin{tabular}{|c|c|c|c|c|c|}
\hline \multicolumn{6}{|c|}{ Upregulated Metabolites in Field Soil (Contaminated Soil) } \\
\hline $\mathbf{t}_{\mathrm{R}}(\mathrm{min}) \_\mathrm{m} / \mathbf{z}$ & t.stat & $p$-Value & Mass Error (ppm) & Metabolite & Metabolism \\
\hline 14.51_91.0081 & -2.9347 & 0.01087 & -60.60257231 & Oxalate & $\begin{array}{c}\text {-Glycine, serine and -threonine metabolism } \\
\text { Purine metabolism }\end{array}$ \\
\hline 14.42_154.9893 & -2.2578 & 0.04045 & 37.38135766 & Oxaloacetate & $\begin{array}{c}\text {-Citrate cycle (TCA cycle) } \\
\text {-Alanine, aspartate and glutamate metabolism }\end{array}$ \\
\hline 15.90_298.0540 & -2.3965 & 0.031075 & -29.87970305 & Paraoxon & Aminobenzoate degradation \\
\hline 15.04_684.2011 & -2.519 & 0.024542 & 29.40706749 & $\begin{array}{l}\text { Streptomycin 6-phosphate } \\
\text { (Streptomyces scabiei) }\end{array}$ & Streptomycin biosynthesis \\
\hline 14.89_281.0509 & -2.521 & 0.024455 & 9.005321238 & Thymidine;Deoxythymidine & Pyrimidine metabolism \\
\hline \multicolumn{6}{|c|}{ Downregulated Metabolites in Field Soil (not Contaminated Soil) } \\
\hline $\mathbf{t}_{\mathrm{R}}(\mathrm{min}) \_\mathrm{m} / \mathbf{z}$ & t.stat & $p$-Value & Mass Error (ppm) & Metabolite & Metabolism (KEGG) \\
\hline 15.74_265.1299 & 19.888 & $5.65 \times 10^{-10}$ & 4.653951133 & Selagine & \\
\hline $15.58 \_242.9242$ & 16.033 & $1.77 \times 10^{-9}$ & 14.54408612 & 2-Iodophenol & \\
\hline 14.85_424.2616 & 15.193 & $5.68 \times 10^{-9}$ & -0.851091841 & $\begin{array}{l}\text { 3beta-(1-Pyrrolidinyl)-5alpha-pregnane- } \\
\text { 11,20-dione }\end{array}$ & \\
\hline 3.09_134.0937 & 14.018 & $2.18 \times 10^{-8}$ & 20.32734589 & Tranylcypromine & \\
\hline 15.43_227.1743 & 13.249 & $1.25 \times 10^{-9}$ & -5.728148531 & Ethambutol & \\
\hline $15.09 \_457.3471$ & 13.097 & $2.71 \times 10^{-9}$ & -6.252920748 & 6alpha-Hydroxycampestanol & Brassinosteroid biosynthesis \\
\hline 11.18_317.2923 & 12.924 & $5.34 \times 10^{-8}$ & -26.49916761 & 17-Propyl-5alpha-androst-2-en-17beta-ol & \\
\hline 11.11_273.2666 & 11.969 & 0.000000119 & -32.65235568 & Taxa-4(5),11(12)-diene;Taxa-4,11-diene & $\begin{array}{c}\text { Diterpenoid biosynthesis } \\
\text { Biosynthesis of terpenoids and steroids }\end{array}$ \\
\hline 12.62_336.2501 & 10.362 & 0.000000468 & 2.422853992 & $(+)$-Prosopinine & \\
\hline 11.51_386.1729 & 10.236 & 0.000000134 & -0.610177392 & Dioncophylline C & \\
\hline $13.58 \_440.3581$ & 9.6318 & 0.000000131 & 16.37290739 & 3beta,4-Dimethyl-4-aza-5alpha-cholestane & \\
\hline
\end{tabular}


Table 4. Cont.

\begin{tabular}{|c|c|c|c|c|c|}
\hline \multicolumn{6}{|c|}{ Downregulated Metabolites in Field Soil (not Contaminated Soil) } \\
\hline $\mathbf{t}_{\mathrm{R}}(\mathrm{min}) \_\mathrm{m} / \mathbf{z}$ & t.stat & $p$-Value & Mass Error (ppm) & Metabolite & Metabolism (KEGG) \\
\hline 11.58_459.489 & 9.3486 & 0.000000793 & 2.22584472 & Hentriacontane & \\
\hline 7.19_285.2403 & 7.484 & $8.64 \times 10^{-8}$ & 7.43701372 & 2-Methoxy-6Z-hexadecenoic acid & \\
\hline 15.51_346.3066 & 6.6331 & 0.00000096 & -32.962628 & Phytoceramide & Sphingolipid metabolism \\
\hline 15.83_909.5309 & 6.4734 & 0.0000143 & 21.06185413 & Zn-Bacterio-chlorophyll a & Porphyrin and chlorophyll metabolism \\
\hline 14.87_445.191 & 4.5605 & 0.00014874 & 1.879348973 & Blasticidin S & \\
\hline 14.63_573.4865 & 2.7964 & 0.01731 & -2.037897249 & 1-O-(1Z-Tetradecenyl)-2-(9Z-octadecenoyl)-sn-glycerol & \\
\hline 14.88_903.5644 & 2.7956 & 0.017375 & 38.74803849 & Bacterio-pheophytins & Porphyrin and chlorophyll metabolism \\
\hline
\end{tabular}

Metabolites were semi-identified by high-resolution UHPLC-Orbitrap-MS. Metabolites in this table were screened statistically significant variables $($ VIP $>1))$ and $(p$-value $<0.05)$. 
The 5-chloro-1,2,4-trihydroxybenzene and Benzene-1,2,4-triol (hydroxyhydroquinone) are also derivative molecules of the benzene compound, one of the molecules discovered in field soil. These were originated from chlorocyclohexane and chlorobenzene degradation or benzoate degradation referring to the Kyoto Encyclopedia of Genes and Genomes (KEGG) Database. Furthermore, naphthyl-2-methyl-succinic acid discovered in field soil is one of the metabolites involved in naphthalene degradation. This was originated from naphthalene, which was one of the combustion products in this study. It is likely that there were trace amounts of naphthalene in field soil because 2-methylindene is an intermediate of the naphthalene production pathway according to [10]. This implies that naphthalene had probably an influence on microbial activity in soil located near the chemical fire site. On the other hand, secondary metabolites were also identified in field soil. The plant's secondary metabolites were located at the chemical accident site, in addition to microbial chemical-defense substances and therapeutic metabolites such as antibiotics and drugs that were identified in field soil (contaminated soil). These are strongly suggested as a biomarker indicating a trace of soil contamination because they have remained in field soil for a long time; substances derived from combustion products tend to be decomposed within a short amount of time in field soil.

\subsubsection{Secondary Metabolites, Antibiotic, and Therapeutic Materials in the Chemical Accident Site}

The carbamoyl phosphate in purine metabolism and streptomycin 6-phosphate in streptomycin biosynthesis was discovered in field soil (Table 4). According to [27], antibiotic synthesis such as streptomycin is related to purine metabolism. Streptomycin metabolism commonly happens with the signaling molecules, (p)ppGpp (guanosine- pentaphosphate) and GTP (guanosine tetra- and pentaphosphates). The purine metabolism induces the signaling materials accumulated by enzymes of purine metabolism aiming (p)ppGpp activation. Moreover, Streptomyces avermitilis joining in streptomycin biosynthesis also was discovered in field soil. These metabolites founded in field soil prove a metabolic and biological relationship. The 2'-deoxyinosine 5'-phosphate and streptomycin 6-phosphate can be secondary metabolites showing a trace of toluene contamination. Moreover, another antibiotic metabolite, 2-hydroxy-beta-keto-L-tyrosyl-[pcp], participating in ciprofloxacin and novobiocin biosynthesis, was also founded in the field soil. Acarbose is an important therapeutic chemical for diabetes (Table 4). Acarbose, a complex oligosaccharide is one of the prominent $\alpha$-glucosidase inhibitors generally for type II diabetes therapy, produced by the bacteria genus, actinoplanes, and streptomyces, which were discovered in field soil in this study [27]. This metabolite seems a product of stress responses because it has been studied that Acarbose is a secondary metabolite unrelated to cell growth $[28,29]$. This material might be produced as a result of Acarbose and validamycin biosynthesis metabolism. This result gives the drug researchers a chance to isolate therapeutically valuable antibiotic compounds when bacteria encounter chemical stress and toxicity.

\subsubsection{Metabolite for Protecting Cell Membrane in Bacteria}

Fatty acid synthesis metabolism is one of the bacterial defense responses resisting a damaged cell membrane by a chemical solvent. Malonyl-[acyl-carrier protein], founded in field soil, belongs to fatty acid biosynthesis in soil bacterial metabolism. Fatty acids are known as one of the regulators related to stress and toxicity. According to [30], the production of fatty acid in the bacterial cell cytoplasm is generally derived from acetyl$\mathrm{CoA}$ and NADPH. Acetyl-CoA commonly is transformed into fatty acids with the ATP (Adenosine triphosphate) energy production process. Fatty acids are the main element of cell membranes, a physical and chemical wall that has a cell protection function in response to environmental stress [30]. Therefore, upregulation of metabolite related to fatty acid production in bacteria implies a defensive behavior against hydrophobic chemical's penetration into the bacterial cell membrane barrier by a virulent chemical such as unburned toluene or its combustion products. Herein, there is another study explaining metabolite production for self-protection. According to [31], hydrophobic compounds such as aro- 
matic molecules can penetrate the cell membrane and cell wall in the cytoplasm. Once an organic pollutant such as a combustion product goes through the cytoplasmic membrane, it induces the membrane to loosen and be damaged. This causes a malfunction of the ion pumping channel importing and exporting a proton and potassium across the cell membrane and makes it difficult for the bacteria to preserve the energy [32]. Bacteria start acting to decrease the fluidity of the cell membrane by trading off bilayer against non-bilayer consisting of phospholipids [33]. The ratio changes of the cytoplasmic membrane allow the toxic chemicals to stop invading and dissolving the cell membrane. On the other hand, if bacteria rigidifies the cell membrane, no more metabolites related to fatty acid synthesis are discovered in field soil, and this means biological recovery in the environment.

\subsubsection{Secondary Metabolites of Plant Surviving from Contaminated Soil}

The 3-nitroacrylate discovered in field soil is an indicator showing the trace of chemical contamination (Table 4). Plants can detoxify toxic chemicals by oxidizing or sugar conjugation. There is a possibility that a plant's metabolite can be emitted into the soil near a rhizosphere with a stress response. When hydrophobic compounds such as aromatic molecules contaminate the soil near the plant's root, it can destroy the membrane and penetrate the root inside. It seems plants that survived from the chemically stressful-soil also tried to detoxify xenobiotics such as combustion products introduced in the plant body. The 3-nitroacrylate emitted from the plant root also was discovered in field soil. According to [34], when an organic pollutant reaches inside the plant body, the plant has a defensive action such as conjugation or degradation. The plant needs to obtain physiological activity such as functionalization, which means transforming a pollutant to another chemical structure joining the rapid detoxification process, and then the conjugate reaction is expected. The conjugate formation with a toxic xenobiotic substance has an oxidative process with activation of oxidase enzyme, which mediates oxidation through substances called cytochrome P450 in plant cells. For this process, activation of electron transportation and circulation by NADPH should be activated for oxidation and hydroxylation, which makes pollutants less toxic in the plant. According to [35], 3-nitroacrylate(beta-nitroacrylate reductase) is a class of beta-nitroacrylate reductase acting on the $\mathrm{CH}-\mathrm{CH}$ group of donors with NAD+ or NADP+ as acceptor (1). This reaction is as follows:

$$
\text { 3-nitropropanoate }+\mathrm{NADP}=3 \text {-nitroacrylate }+\mathrm{NADPH}+\mathrm{H}^{+}
$$

Thus, it is likely that up-regulation of 3-nitroacrylate in plant metabolism in contaminated soil means activation of electron circulation with $\mathrm{NADPH}+$, indicating a resistant behavior against the chemically stressful environment. These metabolites can be suggested as other strong indicators that prove which soil sites had been polluted by the gas cloud because they exist in plants whose metabolism has joined the detoxification process. Herein, Figure 6 shows the up- and downregulated metabolites mentioned above in field soil. All the metabolites studied have contrast intensities between control and field, measured by UHPLC-Orbitrap-MS. The box chart visualization made by normalized intensities clearly presents the activated and inhibited metabolites of microbiology and plant in field soil and it seems that strong metabolic impact in soil ecology by soil contamination derived from gas cloud remains for a long term after the chemical fire accident. 
(a) Upregulated metabolites in field soil (contaminated soil).

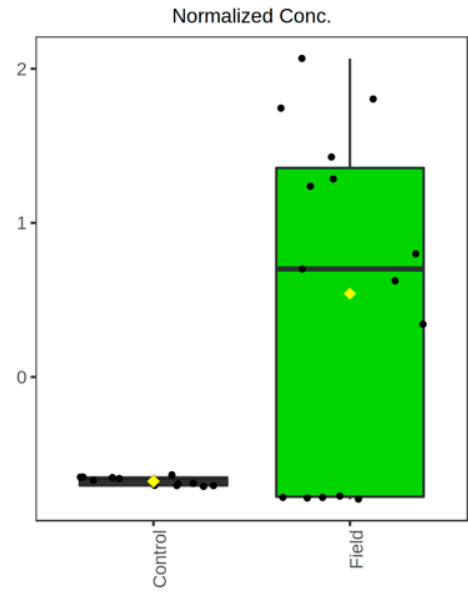

1,4-Dichlorobenzene

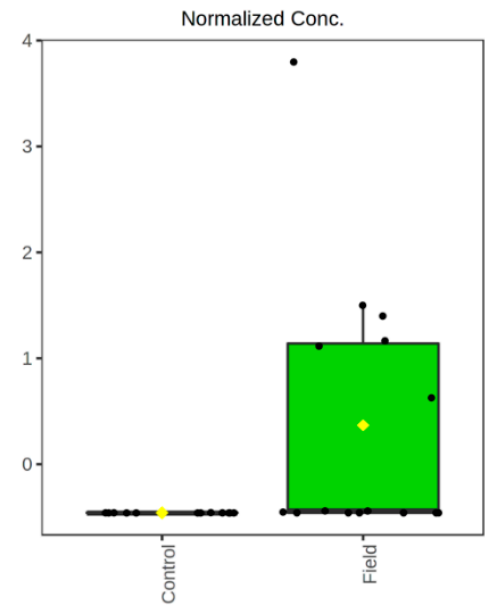

Naphthyl-2-methyl-succinic acid

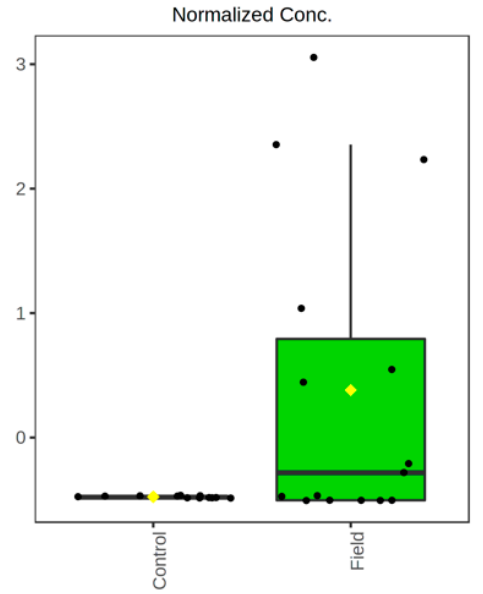

3-Nitroacrylate

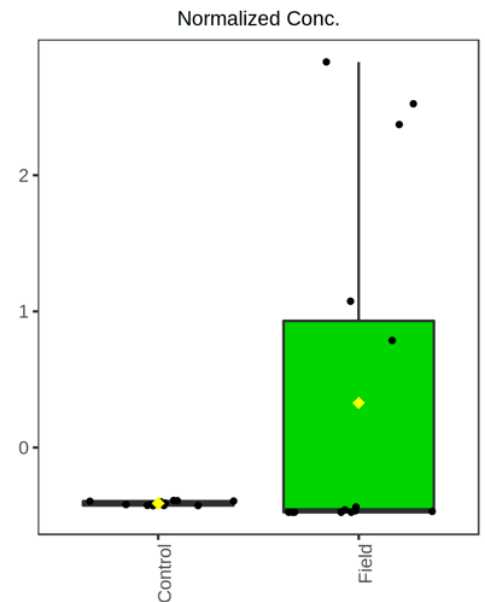

Oxaloacetate

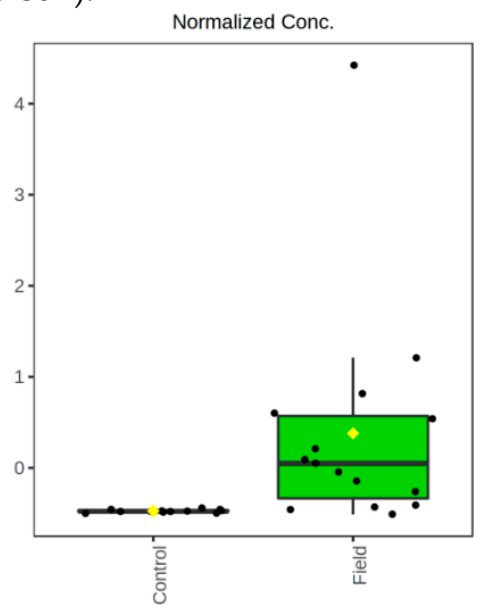

Hydroxyhydroquinone

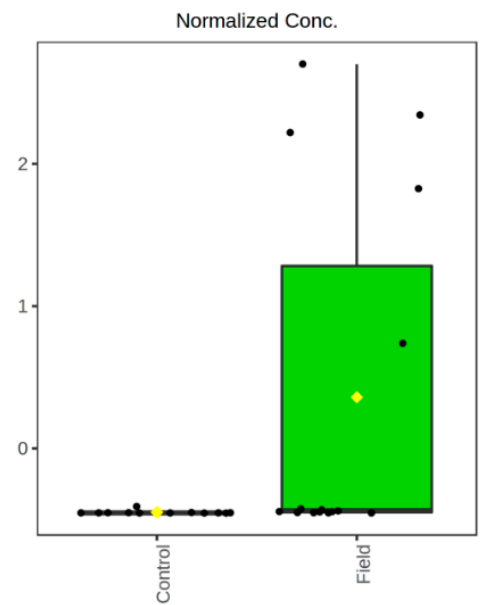

Streptomycin 6-phosphate

(b) Downregulated metabolites in field soil (contaminated soil).

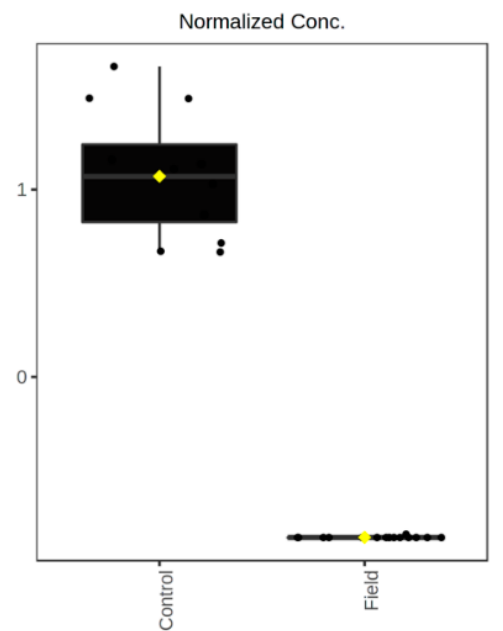

Selagine

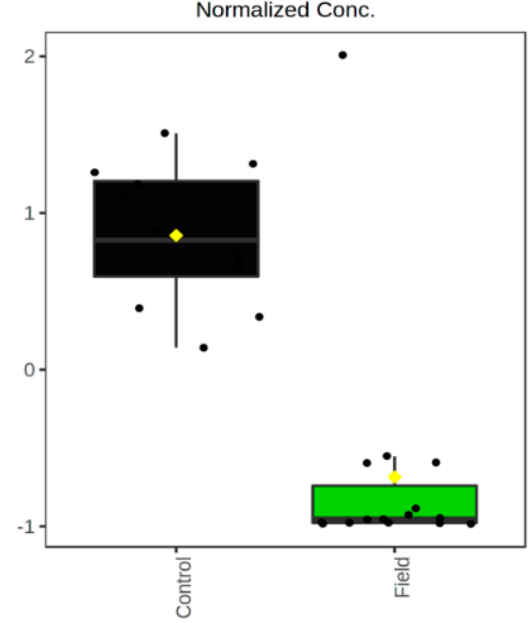

Phytoceramide

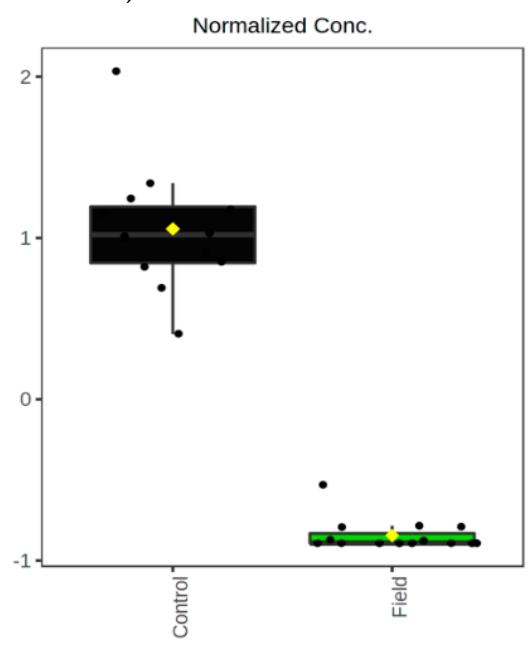

2-Iodophenol

Figure 6. Cont. 


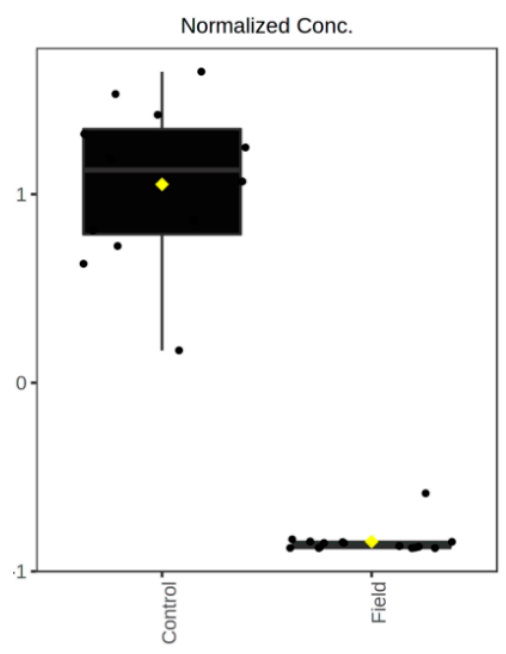

3beta-(1-Pyrrolidinyl)-5alphapregnane-11,20-dione

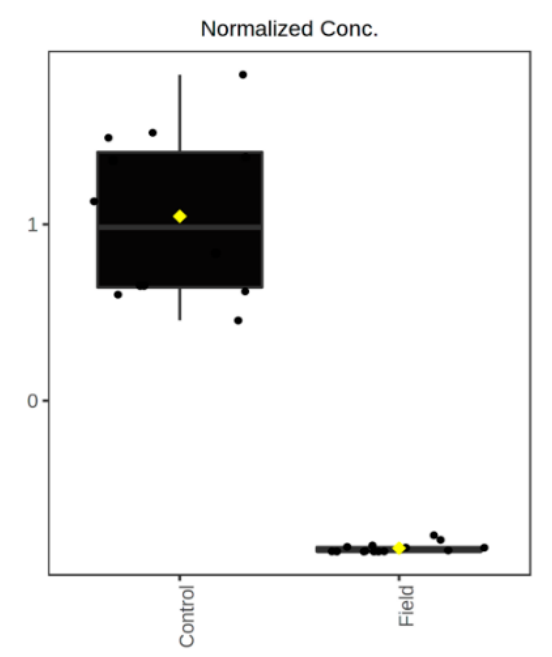

Tranylcypromine

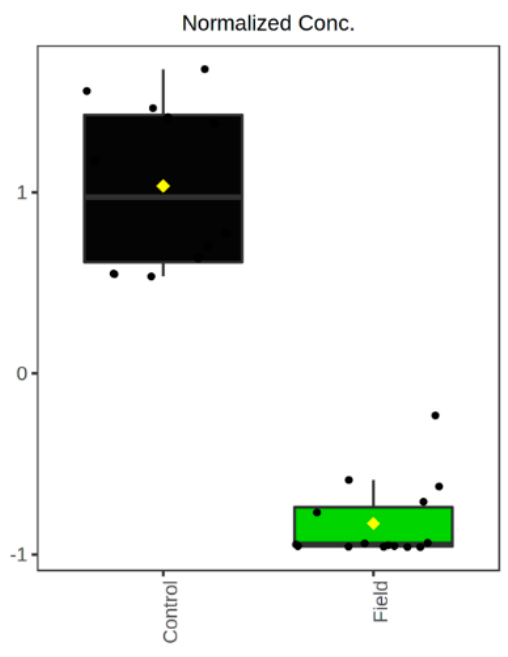

Ethambutol

Figure 6. The normalized peak intensity of proposed metabolites as the metabolite biomarkers in field soil (contaminated soil); raw peak intensity of LC-MS was normalized by statistical analysis using data filter (relative standard deviation, (RSD)), normalization by sum, and data scaling (Pareto scaling).

\subsection{Microbial Community Analysis in Field Soil}

To monitor and identify the prominent bacteria affecting the major metabolites and the effect of toluene exposal on the fate of the microbial community, 16s rRNA analysis was conducted (Figure 7). The Proteobacteria (34\%), Actinobacteria (29\%) and Chloroflexi $(9 \%)$, Acidobacteria $(7 \%)$, and Cyanobacteria (5\%) were dominant bacteria phylums in control soil. This composition of phyla was slightly changed after the toluene exposure (Table 5). Cyanobacteria were decreased below $1 \%$ and another phylum composition was almost similar. Actinobacteria and Proteobacteria are well-known aerobic steroid-degrading bacteria [36]. These strains were mainly isolated from soil. Arthrobacter globiformis, Streptomyces scabiei, Sphingomonas lutea, and Sphingomonas sediminicola were major groups in control soil. These bacteria were decreased after toluene exposure, while Bradyrhizobium japonicum, Mycobacterium farcinogenes, Hamadaea flava, and Sphingomonas pruni groups were increased after toluene exposure (Table 5). Arthrobacter globiformis can oxidize ammonium ions and biodegrade various pollutants [37,38]. It was expected that Arthrobacter would break down the aromatic compound when contaminated with toluene. The Streptomyces scabiei attend the steroid degradation pathway [39]. Bradyrhizobium japonicum was reported as toluene degrader [40]. Consequently, the combination of soil microbiome and metabolome analysis can provide comprehensive insight into the ecological impact of the emerging contaminants. In this study, the majority of identified bacteria in field soil would affect the major metabolites discovered in field soil (Tables 4 and 5).

To propose a relationship between toluene combustion products and detected metabolites in toluene-affected soils, it should be noted that streptomycin 6-phosphate and naphthyl-2-methyl-succinic acid degraded from naphthalene have a metabolic relationship with Streptomyces scabiei group discovered in contaminated soil (Table 5) [41,42]. In the control soil, DNA count of Streptomyces scabiei group was about three times more than field soil (Table 5). It is expected that the population of Streptomyces scabiei group in the field soil decreased instantly due to the acute toxicity of toluene and its combustion by-products in soil bacteria. Damage to the cytoplasmic membrane happens instantly to the bacteria cell membrane, resulting in the loss of the cations $\mathrm{Mg}^{2+}$ and $\mathrm{Ca}^{2+}$ [43]. Moreover, these aromatic compounds are so volatile and not easily soluble in water that toxicity duration can last due to chemicals adsorbed on clay minerals for a long term; even rainfall leaches 
into ground soil. However, the small number of Streptomyces scabiei group that decomposes naphthalene appears to have barely survived for a while, as shown in Table 5.

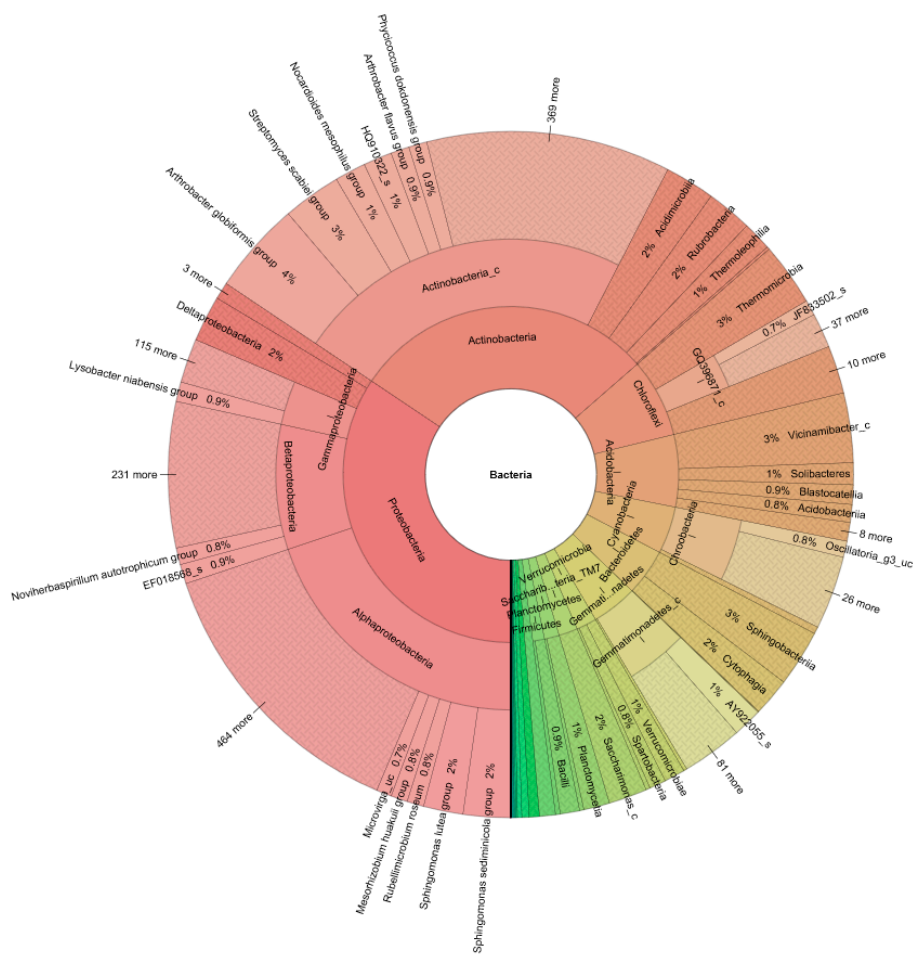

(a)

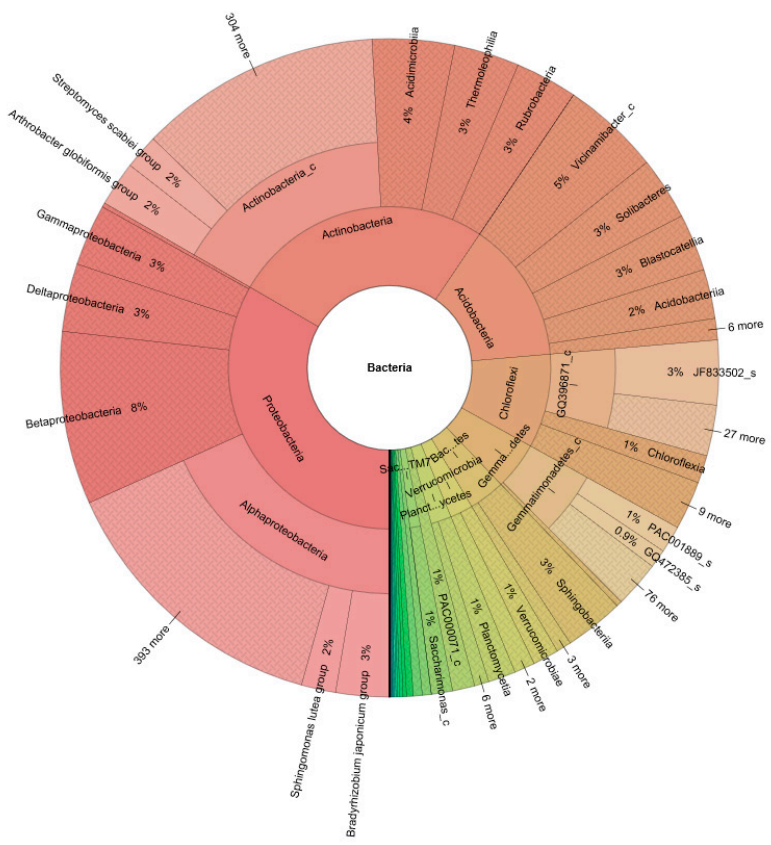

(b)

Figure 7. The 16s rRNA sequencing results of soil bacteria community in (a) control soil (b) field soil (contaminated). 
Table 5. Fate of phylum and species of bacteria in control and field soils (contaminated soil).

\begin{tabular}{ccc}
\hline Phylum & Control & Field \\
\hline Proteobacteria & 34 & 33 \\
Actinobacteria & 29 & 26 \\
Chloroflexi & 8 & 9 \\
Acidobacteria & 7 & 14 \\
Cyanobacteria & 5 & $<1$ \\
\hline Species & Control & Field \\
\hline Arthrobacter globiformis group & 3825 & 933 \\
Streptomyces scabiei group & 2424 & 722 \\
Sphingomonas lutea group & 1644 & 714 \\
Sphingomonas sediminicola group & 1967 & 266 \\
Nocardioides mesophilus group & 1292 & 116 \\
Lysobacter niabensis group & 814 & 6 \\
Bradyrhizobium japonicum group & 319 & 1112 \\
Mycobacterium farcinogenes group & 54 & 238 \\
Hamadaea flava & 56 & 140 \\
Sphingomonas pruni group & 47 & 118 \\
\hline
\end{tabular}

Unit: DNA Counts (16s rRNA).

\section{Conclusions}

This study proposed the possibility of soil contamination by gas cloud when a chemical fire accident occurs. Moreover, the biomarker such as soil microbiological and plant metabolites were excavated in contaminated soil, using metabolomics.

Firstly, it was proposed that toluene derivatives such as naphthalene, 2-methylindene, ethylbenzene, etc. were identified as combustion products in the gas cloud; then, it was studied that a specific atmospheric condition such as conversion layer can trigger contacts between gas cloud and ground soil. This research also assessed the impacts of toluene combustion on microbial community and metabolites of contaminated soil in South Korea using $16 \mathrm{~S}$ rRNA sequencing and metabolomics. The obtained results show remarkably increased metabolites such as 1,4-dichlorobenzene, 5-chloro-1,2,4-trihydroxybenzene, hydroxyhydroquinone, naphthyl-2-methyl-succinic acid, oxaloacetate, and streptomycin 6-phosphate. Moreover, the metabolites in plants surviving in contaminated soil were also identified as 3-nitroacrylate, related to the detoxification process in plant metabolism by its self-protection function against chemical stress. In addition, the downregulated biomarker were also identified as selagine, 3beta-(1-pyrrolidinyl)-5alpha-pregnane-11,20-dione, and phytoceramide. Toluene exposure led to the shift in bacterial composition and structure. Arthrobacter globiformis, Streptomyces scabiei, Sphingomonas lutea, Sphingomonas sediminicola, Nocardioides mesophilus, and Lysobacter niabensis groups were significantly decreased, while Bradyrhizobium japonicum and Mycobacterium farcinogenes groups were increased, but there was only a weak effect on the bacterial diversity. A close connection between bacterial communities and metabolic profile in soil was also observed, suggesting their consistent response to environmental stress. Further studies are needed to identify the bacterial community producing secondary metabolites that respond to toluene stress of soil microbiology and plant. In this research, few links with bacteria and its metabolites were found. Accordingly, whole-genome sequencing of bacteria will provide better information to find out the causal relationship between soil bacteria and upregulated metabolites in the next study. As a result, it is remarkable that soil contamination, not by chemical leakage but by chemical fire accidents, can strongly impact the soil ecology, considering that the alteration of bacteria community and metabolites are clearly identified, even in soil that has been contaminated for a long term, e.g., three years. Additionally, hydroxyhydroquinone discovered in field soil is a representative breakdown material of aromatic compounds. Soil contamination by gas cloud has been considered a low concentration's contamination, but the discovery of hydroxyhydroquinone in field soil implies biodegradation of toluene, and its combustion products degraded slowly, depending on the soil environment, and 
affect the soil microbiology even after three years of the toluene fire accident. The identified breakdown materials and metabolites in filling soil can point to traces of soil contamination.

Supplementary Materials: The following are available online at https:/ /www.mdpi.com/article/10 $.3390 / \min 11040372 / \mathrm{s} 1$, Figure S1: Total ion chromatogram showing combustion products suggested in Table 1, list of products detected from combustion gas and pollutants in soil, Figure S2: Chemical pathway explaining the formation of naphthalene and 2-methylindene [10].

Author Contributions: Conceptualization, J.C. and J.L.; investigation, J.J. and N.K.; data curation, J.J., H.P., S.-T.Y. and M.K.; writing—original draft preparation, J.J.; writing-review and editing, Y.A. and K.P.; visualization, J.J.; supervision, J.C.; project administration, J.C.; funding acquisition, J.C. All authors have read and agreed to the published version of the manuscript.

Funding: This work was supported by Korea Environment Industry and Technology Institute (KEITI) through the Chemical Accident Prevention Technology Development Project, funded by the Korea Ministry of Environment(MOE) (2020001960001).

Data Availability Statement: Not applicable.

Conflicts of Interest: The authors declare no conflict of interest.

\section{Appendix A}

The instrumental condition of GC-MS was nearly the same as previous research [38]. GC-MS was prepared with a combination of a 7890A gas chromatograph (Agilent, Santa Clara, CA, USA) and a 5975C mass selective detector (MSD) (Agilent). Injection of the sample was performed by Combi-PAL autosampler (CTC Analytics AG, Zwingen, Switzerland). All the samples were analyzed using the column ultra-2 (cross-linked $5 \%$ phenylmethylsiloxane, $25 \mathrm{~m} \times 0.2 \mathrm{~mm}$ I.D $\times 0.33 \mu \mathrm{m}$ film thickness) (Agilent, J\&W, Santa Clara, CA, USA). The carrier gas, Helium ( $99.9999 \%$ ) flowed at $1.0 \mathrm{~mL} / \mathrm{min}$ and the split ratio was 20:1. The inlet temperature was $270{ }^{\circ} \mathrm{C}$, and the transfer line temperature was $280^{\circ} \mathrm{C}$. The oven program was as follows: the initial temperature was $40{ }^{\circ} \mathrm{C}$ for $5 \mathrm{~min}$, ramped $10^{\circ} \mathrm{C} / \mathrm{min}$ to $150{ }^{\circ} \mathrm{C}$ for $0 \mathrm{~min}, 40^{\circ} \mathrm{C} / \mathrm{min}$ to 310 for $1 \mathrm{~min}$. The ion source and quadrupole temperatures in the mass spectrometer were controlled at $230{ }^{\circ} \mathrm{C}$ and $150{ }^{\circ} \mathrm{C}$, respectively. The solvent delay was $3.5 \mathrm{~min}$, and the selected ion monitoring (SIM) mode was performed to quantify the compounds in the samples. The instrument was tuned by perfluorotributylamine (PFTBA).

LC system coupled with Orbitrap VelosPro MS (Thermo Fisher Scientific, Waltham, MA, USA) was used for non-target metabolites analysis. All metabolites were separated using a column (BEH-C18 $(100 \mathrm{~mm}$ length $\times 2.1 \mathrm{~mm}$ i.d., $1.7 \mu \mathrm{m}$ particle size; Waters, Milford, MA, USA)) at $400 \mu \mathrm{L} / \mathrm{min}$. After injection, the mobile phase consisting of A $(0.1 \%$ formic acid in DW) and B ( $0.1 \%$ formic acid in acetonitrile) was controlled as follows: 0-3 $\mathrm{min}$ at $5 \% \mathrm{~B} ; 3-10 \mathrm{~min}, 5 \%-65 \% \mathrm{~B} ; 10-11.5 \mathrm{~min}, 65 \%-90 \% \mathrm{~B} ; 11.5-16 \mathrm{~min}, 90 \% \mathrm{~B}$; 16-16.1 $\mathrm{min}, 90-5 \% \mathrm{~B} ; 16.1-19 \mathrm{~min}, 5 \% \mathrm{~B}$. The gradient was returned to the initial condition $(5 \% \mathrm{~B})$ and this step was held for $4 \mathrm{~min}$ before the next sample was run. The column was maintained at $40^{\circ} \mathrm{C}$; the total run time was $16 \mathrm{~min}$. A $5 \mu \mathrm{L}$ aliquot of each sample was injected for analysis. The samples were kept at $4{ }^{\circ} \mathrm{C}$ in an autosampler during the analysis. MS was operated under the following optimized conditions: ion spray voltage of $3.8 \mathrm{kV}$ and capillary temperature of $320^{\circ} \mathrm{C}$. Nitrogen was used as the sheath gas at 20 arbitrary units. Each sample was analyzed in FTMS (Fourier Transform Mass Spectrometr) full scan mode at a resolving power of 60,000 and the $\mathrm{m} / \mathrm{z}$ ranges were set to $50-1600$ in profile mode. Metabolites analysis was performed. The instrument is Ultimate 3000 (Thermo Scientific Domex, Waltham, MA, USA).

\section{References}

1. Jung, S.; Woo, J.; Kang, C. Analysis of severe industrial accidents caused by hazardous chemicals in South Korea from January 2008 to June 2018. Saf. Sci. 2020, 124, 104580. [CrossRef]

2. National Institute of Chemical Safety, Integraed Information System of Chemical (National Institute of Chemical Safety). Available online: https://icis.me.go.kr/search/searchType2.do (accessed on 1 February 2021). 
3. Kang, I.-S.; Xi, J.; Hu, H.-Y. Photolysis and photooxidation of typical gaseous VOCs by UV Irradiation: Removal performance and mechanisms. Front. Environ. Sci. Eng. 2018, 12, 8. [CrossRef]

4. Agency, E.E. Temperature Inversion Traps Pollution at Ground Level. European Environment Agency. Available online: https: //www.eea.europa.eu/media/infographics/temperature-inversion-traps-pollution-at/view (accessed on 1 February 2021).

5. Yang, S.; Jeon, K.; Kang, D.; Han, C. Accident analysis of the Gumi hydrogen fluoride gas leak using CFD and comparison with post-accidental environmental impacts. J. Loss Prev. Process Ind. 2017, 48, 207-215. [CrossRef]

6. Moussa, N.; Devarakonda, V. Prediction of Toxic Emissions from Chemical Fire and Explosion. Fire Saf. Sci. 2014, 11, 1457-1468. [CrossRef]

7. Ahn, M.S.; Lee, H.E.; Cheon, K.S.; Joo, H.G.; Son, B.-S.; Ochang Chemical Safety Community. Feasibility Evaluation of Designated Quantities for Chemicals Requiring Preparation for Accidents in the Korean Chemical Accident Prevention System. Int. J. Environ. Res. Public Health 2020, 17, 1927. [CrossRef] [PubMed]

8. Long, A.; Zhang, H.; Lei, Y. Surfactant flushing remediation of toluene contaminated soil: Optimization with response surface methodology and surfactant recovery by selective oxidation with sulfate radicals. Sep. Purif. Technol. 2013, 118, 612-619. [CrossRef]

9. Fullerr, M.E. Effects of Toluene on Microbially-Mediated Processes Involved in the Soil Nitrogen Cycle. Microb. Ecol. 1995, 32, 171-184. [CrossRef]

10. Zhao, L.; Kaiser, R.I.; Lu, W.; Xu, B.; Ahmed, M.; Morozov, A.N.; Mebel, A.M.; Howlader, A.H.; Wnuk, S.F. Molecular mass growth through ring expansion in polycyclic aromatic hydrocarbons via radical-radical reactions. Nat. Commun. 2019, 10, 3689. [CrossRef]

11. Yost, L.J.; Hartemink, A.E. How deep is the soil studied-An analysis of four soil science journals. Plant Soil 2020, 452, 5-18. [CrossRef]

12. Kim, N.; Ahn, Y.; Jo, J.; Pyo, H.; Lee, J.; Choi, J. Soil assessment after chemical accidents using metabolic profiling and microbial community evaluation. Chemosphere 2021, 268, 129362. [CrossRef]

13. Chu, T.C.; Buras, Z.J.; Smith, M.C.; Uwagwu, A.B.; Green, W.H. From benzene to naphthalene: Direct measurement of reactions and intermediates of phenyl radicals and acetylene. Phys. Chem. Chem. Phys. 2019, 21, 22248-22258. [CrossRef] [PubMed]

14. Battin-Leclerc, F. Detailed chemical kinetic models for the low-temperature combustion of hydrocarbons with application to gasoline and diesel fuel surrogates. Prog. Energy Combust. Sci. 2008, 34, 440-498. [CrossRef]

15. Li, Y.; Yuan, W.; Li, T.; Li, W.; Yang, J.; Qi, F. Experimental and kinetic modeling investigation of rich premixed toluene flames doped with n-butanol. Phys. Chem. Chem. Phys. 2018, 20, 10628-10636. [CrossRef] [PubMed]

16. Gabriel da Silva, C.-C.C.; Bozzelli, J.W. Toluene combustion: Reaction paths, thermochemical properties, and kinetic analysis for the methylphenyl radical $+\mathrm{O}_{2}$ reaction. J. Phys. Chem. 2007, 35, 8663-8676. [CrossRef]

17. Ninomiya, J.S.; Biggers, B. Effects of toluene content in fuel on aromatic emissions in the exhaust. J. Air Pollut. Control 1970, 20, 609-611. [CrossRef]

18. Levitin, J. A Verification of a New Coastal Area Dispersion Model. Air Pollution Modeling and Its Application XIII; Springer: Boston, MA, USA, 2000; pp. 589-596.

19. Anda, A.; Illes, B. Impact of Simulated Airborne Soot on Maize Growth and Development. J. Environ. Prot. 2012, 3, 773-781.

20. Ruiz, J.; Bilbao, R.; Murillo, M.B. Adsorption of Different VOC onto Soil Minerals from Gas Phase Influence of Mineral Type of VOC and Air Humidity. Environ. Sci. Technol. 1998, 32, 1079-1084. [CrossRef]

21. Park, W.P.; Chang, K.M.; Koo, B.J.; Hyun, H.N. Cation Exchange Capacity in Korean Soils Determined by the Copper(II) Acetate Spectrophotometry Method. Korean J. Soil Sci. Fertil. 2017, 50, 653-662.

22. Breus, I.P.; Mishchenko, A.A. Sorption of volatile organic contaminants by soils (a review). Eurasian Soil Sci. 2006, 39, 1271-1283. [CrossRef]

23. Singh, R.; Lemire, J.; Mailloux, R.J.; Appanna, V.D. A novel strategy involved in [corrected] anti-oxidative defense: The conversion of NADH into NADPH by a metabolic network. PLoS ONE 2008, 3, e2682. [CrossRef]

24. Iessi, E.; Marconi, M.; Manganelli, V.; Sorice, M.; Malorni, W.; Garofalo, T.; Matarrese, P. On the role of sphingolipids in cell survival and death. Int. Rev. Cell Mol. Biol. 2020, 351, 149-195.

25. Kunz, T.C.; Kozjak-Pavlovic, V. Diverse Facets of Sphingolipid Involvement in Bacterial Infections. Front Cell Dev. Biol. 2019, 7, 203. [CrossRef] [PubMed]

26. Shi, X.; Wang, Q.; Violi, A. Chemical pathways for the formation of benzofuran and dibenzofuran in combustion. Combust. Flame 2020, 212, 216-233. [CrossRef]

27. Sivapragasam, S.; Grove, A. The Link between Purine Metabolism and Production of Antibiotics in Streptomyces. Antibiotics 2019, 8, 76. [CrossRef]

28. Ren, F.; Chen, L.; Xiong, S.; Tong, Q. Enhanced acarbose production by Streptomyces M37 using a two-stage fermentation strategy. PLoS ONE 2017, 12, e0166985. [CrossRef]

29. Wang, Y.-J.; Liu, L.-L.; Feng, Z.-H.; Liu, Z.-Q.; Zheng, Y.-G. Optimization of media composition and culture conditions for acarbose production by Actinoplanes utahensis ZJB-08196. World J. Microbiol. Biotechnol. 2011, 27, 2759-2766. [CrossRef]

30. Sun, Y.; Wilkinson, B.J.; Standiford, T.J.; Akinbi, H.T.; O’Riordan, M.X.D. Fatty acids regulate stress resistance and virulence factor production for Listeria monocytogenes. J. Bacteriol. 2012, 194, 5274-5284. [CrossRef] 
31. Murinova, S.; Dercova, K. Response mechanisms of bacterial degraders to environmental contaminants on the level of cell walls and cytoplasmic membrane. Int. J. Microbiol. 2014, 2014, 873081. [CrossRef]

32. Diefenbach, R.; Heipieper, H.J.; Keweloh, H. Conversion of cis Unsaturated Fatty Acids to trans, a Possible Mechanism for the Protection of Phenol-Degrading Pseudomonas putida P8 from Substrate Toxicity. Appl. Environ. Microbiol. 1992, 58, $1847-1852$.

33. Ghorbal, S.K.; Ghorbal, B.; Chatti, A.; Sethom, M.M.; Maalej, L.; Mihoub, M.; Kefacha, S.; Feki, M.; Hassen, A.L.A. Changes in membrane fatty acid composition of Pseudomonas aeruginosa in response to UV-C radiations. Curr. Microbiol. 2013, 67, 112-117. [CrossRef] [PubMed]

34. Kvesitadze, A.; Khatisashvili, G.; Sadunishvili, T.; Ramsden, J.J. Biochemical Mechanisms of Detoxification in Higher Plants; Springer: Berlin/Heidelberg, Germany, 2006.

35. Shaw, P.D. Biosynthesis of nitro compounds. III. The enzymatic reduction of beta-nitroacrylic acid to beta-nitropropionic acid. Biochemistry 1967, 6, 2253-2260. [CrossRef]

36. Merino, E.; Barrientos, A.; Rodríguez, J.; Naharro, G.; Luengo, J.M.; Olivera, E.R. Isolation of cholesterol- and deoxycholatedegrading bacteria from soil samples: Evidence of a common pathway. Applied Microbiol. Biotechnol. 2013, 97, 891-904. [CrossRef]

37. Whitman, W.; Goodfellow, M.; Kämpfer, P.; Busse, H.-J.; Trujillo, M.; Ludwig, W.; Suzuki, K.-I.; Parte, A. (Eds.) Bergey's Manual of Systematic Bacteriology; Springer: New York, NY, USA, 2012; Volume 5.

38. O'Loughlin, E.J.; GSims, K.; Traina, S.J. Biodegradation of 2-methyl, 2-ethyl, and 2-hydroxypyridine by an Arthrobacter sp. isolated from subsurface sediment. Biodegradation 1999, 10, 93-104. [CrossRef] [PubMed]

39. Fofana, B.; Somalraju, A.; Fillmore, S.; Zaidi, M.; Main, D.; Ghose, K. Comparative transcriptome expression analysis in susceptible and resistant potato (Solanum tuberosum) cultivars to common scab (Streptomyces scabies) revealed immune priming responses in the incompatible interaction. PLoS ONE 2020, 15, e0235018. [CrossRef] [PubMed]

40. Sudtachat, N.; Ito, N.; Itakura, M.; Masuda, S.; Eda, S.; Mitsui, H.; Kawaharada, Y.; Minamisawa, K. Aerobic Vanillate Degradation and C1 Compound Metabolism in Bradyrhizobium japonicum. Applied Environ. Microbiol. 2009, 75, 5012. [CrossRef]

41. Balachandran, C.; Duraipandiyan, V.; Balakrishna, K.; Ignacimuthu, S. Petroleum and polycyclic aromatic hydrocarbons (PAHs) degradation and naphthalene metabolism in Streptomyces sp. (ERI-CPDA-1) isolated from oil contaminated soil. Bioresour. Technol. 2012, 112, 83-90.

42. Bignell, D.R.D. Streptomyces scabies 87-22 Contains a Coronafacic Acid-Like Biosynthetic Cluster That Contributes to PlantMicrobe Interactions. Am. Phytopathol. Soc. 2010, 23, 161-175. [CrossRef]

43. Nahar, N.; Alauddin, M.; Quilty, B. Toxic efects of toluene on the growth of activated sludge bacteria. World J. Microbiol. Biotechnol. 2000, 6, 307-311. [CrossRef] 